\title{
DERECHO INTERNACIONAL PRIVADO Y DERECHO MARÍTIMO INTERNACIONAL: COMPETENCIA JUDICIAL INTERNACIONAL Y ACUERDOS ATRIBUTIVOS DE JURISDICCIÓN EN LA LNM
}

\author{
PRIVATE INTERNATIONAL LAW AND MARITIME \\ INTERNATIONAL LAW: JURISDICTION AND JURISDICTION \\ AGREEMENTS IN LAW OF MARITIME NAVIGATION
}

\author{
Unai BeLintXon Martin \\ Profesor Contratado Doctor de Derecho Internacional Privado \\ Universidad Pública de Navarra (UPNA) \\ Recibido: 16.03.2020 / Aceptado: 04.04.2020 \\ DOI: https://doi.org/https://doi.org/10.20318/cdt.2020.5604
}

\begin{abstract}
Resumen: Este estudio tiene por objeto, desde la perspectiva del Derecho internacional privado, el análisis y valoración crítica de la evolución normativa experimentada en el sector del Derecho marítimo internacional. En particular este trabajo tiene por objeto analizar la interpretación por parte de nuestros tribunales de las normas sobre jurisdicción contenidas en el RBI bis y en la Ley de Navegación Marítima y la interacción de los diversos bloques normativos en presencia (Derecho europeo, Derecho nacional y Derecho internacional). Desde la perspectiva de análisis de los operadores del sector se abordará en qué medida el objetivo de seguridad jurídica se está logrando o si por el contrario la ausencia de reglas claras de compatibilidad entre esas diversas normas acaba generando incertidumbres que perjudican a todo el elenco de intereses en presencia.

Palabras clave: Derecho internacional privado, Derecho marítimo, cláusulas de jurisdicción, Ley de Navegación Marítima, Derecho europeo.

Abstract: This paper endeavours to address some of the disparate, legally releevant and yet controversial issues that arise out the international carriage of goods by sea. Given the multiple perspectives from which sea transport law may by observed and assessed, a certain degree of definitional work is essential in order to identify the issues involved from a private international law perspective. In particular, this study aims to analyze the interpretation by our courts of the rules on international jurisdiction contained in Brussels IBis and in the law of maritime navigation and the interaction between normative blocks (European Law, National Law and international law). From the operators sector's point of view, it will tackle that when the aim of the legal security is achievingor on the contrary the absence of the compatibility of the rules between those deserve rules finishes producing doubts that harm all the interests of the present cast.
\end{abstract}

Keywords: Private international Law, Maritime Law, jurisdictions clauses, Law of Maritime Navigation, European Law.

Sumario: I. Consideraciones preliminares / Contextualización. II. Derecho marítimo y acuerdos atributivos de jurisdicción. III. Competencia judicial internacional y acuerdos atributivos de jurisdicción en LNM. Soluciones de nuestros tribunales. 1. Acuerdo atributivo de jurisdicción inserto en conocimiento de embarque y prevalencia del artículo 25 RBI bis sobre el artículo 468 LNM. 2. Modificación del acuerdo atributivo de jurisdicción del artículo 25 RBI bis por sumisión tácita 
del artículo 26 del RBI bis. Primacía del Derecho europeo sobre el artículo 468 LNM. 3. Acuerdo atributivo de jurisdicción inserto en conocimiento de embarque. No apreciación de prevalencia del artículo 25 RBI bis sobre el artículo 468 LNM y la eficacia traslativa del conocimiento de embarque del artículo 251 LNM. 4. La inaplicación del acuerdo atributivo de jurisdicción inserto en carta de porte marítima suscrita entre transportista contractual y transportista efectivo al cargador que suscribió conocimiento de embarque sin incorporación de sumisión expresa con el porteador contractual. IV. Consideraciones finales.

\section{Consideraciones Preliminares / Contextualización}

1. El Derecho del transporte marítimo en su dimensión internacional, las reglas sobre competencia judicial internacional contenidas en las normas internacionales, europeas y nacionales aplicables al sector $^{1}$, la autonomía de la voluntad, junto a los acuerdos atributivos de jurisdicción constituyen en esencia el hilo conductor de este trabajo que pretende abordar los criterios seguidos por nuestros Tribunales en la aplicación e interpretación para dichas cuestiones de la Ley 14/2014, de 24 de julio, de Navegación Marítima (LNM). En efecto, se pretende identificar y analizar algunos de los pronunciamientos de la práctica jurisprudencial de estos años de vigencia de la norma marítima que han desarrollado nuestros Tribunales sobre algunas de las cuestiones más controvertidas y con mayor relevancia jurídica que afloran en este particular ámbito de nuestra disciplina del Derecho internacional.

2. Analizar la interpretación y aplicación jurisprudencial ofrecida por nuestros Tribunales sobre el marco legal aplicable en España y en la UE a este subsector de nuestra compleja y apasionante disciplina requiere de un profundo examen que permita identificar y proyectar sobre el ámbito internacional la concreta problemática que se presenta en el ámbito marítimo a través de particulares manifestaciones como son, entre otras cuestiones, las llamadas cláusulas flotantes de jurisdicción y las cláusulas de arbitraje.

3. La pluralidad de aproximaciones que el Derecho del transporte marítimo admite ${ }^{2}$ en lo tocante a su objeto de estudio y reflexión ${ }^{3}$, exige de manera ineludible una labor de acotación previa que advierta la vertiente iusprivatista de nuestra disciplina, sin desatender otras a las que, en ocasiones, necesariamente habrá que aproximarse con la finalidad inequívoca de ofrecer una respuesta analítica conforme a las características inherentes del Derecho internacional privado actual, caracterizado por una sugerente y atractiva especialización por sectores ${ }^{4}$.

4. En particular, estas reflexiones pretenden incidir en algunas de las cuestiones más controvertidas del Derecho del transporte marítimo y con mayor impacto práctico sobre la realidad comercial internacional ${ }^{5}$.

\footnotetext{
${ }^{1}$ Respecto a la pluralidad de bloques normativos coexistentes y la cascada de la especificidad, puede verse J.J. ÁLVAREZ RuBio, "Las reglas de especificidad como cauce para superar los conflictos normativos entre el Derecho comunitario y los Convenios internacionales en materias especiales", La Ley, 29 de octubre de 2010, pp. 1-6.

2 Sobre este particular y las múltiples aproximaciones que permite el Derecho marítimo: G. DiEnA, "Principes du Droit international privé maritime", $R$. des $C$., 1935, t. 51, pp. 405 y ss.

${ }^{3}$ U. BelintXon Martín, "Dumping Social, desarmonización socio-laboral y Derecho internacional privado: la des-Unión Europea”, AEDIPr, t. XVI, 2016, pp. 611-642.

${ }^{4}$ Sobre ello, es clave la reflexión de: J.D. GonzÁlez CAmpos, "Diversification, Spécialisation, Flexibilisation et Materialisation des régles de Droit International Privé”, $R d e s C$, t. 287, 2002, pp. 156 y ss. Véase de igual forma J.J. Álvarez RuBIo, Las Lecciones Jurídicas del Caso Prestige: Prevención, Gestión y Sanción frente a la contaminación marina por hidrocarburos, Pamplona, Aranzadi, 2011.

${ }^{5}$ Sobre la fundamental importancia del transporte para nuestra economía, nuestra sociedad y desarrollo interior aunque en referencia expresa al sector por carretera, entre otros estudios puede verse: F. JAVIER PIÑALES LeAL, Régimen Jurídico del transporte por carretera, Madrid, Marcial Pons, 1993, pp. 32-43.
} 
5. Dicho esto, la nota de internacionalidad de nuestra disciplina y su propensión hacia su uniformidad normativa internacional ${ }^{6}$ delimitada hoy por la europeización del Derecho privado ${ }^{7}$ que tiene su origen en el Tratado de Ámsterdam ${ }^{8}$, consolidada y reforzada en la actualidad tras diez años de vigencia del Tratado de Lisboa ${ }^{9}$, así como la dimensión o proyección externa de este proceso ${ }^{10}$, refleja nítidamente una problemática específica ${ }^{11}$, y es que dicho proyecto europeo ${ }^{12}$ no está viviendo su momento más álgido tras la activación del Brexit del Reino Unido $^{13}$ y esto incide significativamente en la seguridad jurídica y en la previsibilidad ${ }^{14}$ de resultado provocando distorsiones a los diferentes agentes y operadores $^{15}$. Distorsiones que podrían consumarse en lo que respecta a las cláusulas de jurisdicción y arbitraje incluidas en conocimientos de embarque si para la relación con Reino Unido el sistema procesal europeo diseñado y aplicable en la actualidad, con origen en el Convenio de Bruselas de 1968, claudica en favor de la aplicación a tal materia de las normas contenidas en la Ley de Navegación Marítima ${ }^{16}$. Desde luego, los nuevos tiempos de la realidad internacional requieren de una mayor integración ${ }^{17} \mathrm{y}$ del fortalecimiento de las bases de un proyecto común, el europeo, que se activó hace ya 63 años con el Tratado de Roma de $1957^{18}$.

6. En efecto, la distinta interpretación de las normas europeas y nacionales de aplicación al ámbito de estudio genera cierto estado de inseguridad jurídica e inquietud que lastima el habitual desarrollo del estado de las cosas y que parece deslegitima en parte nuestro proyecto europeo ${ }^{19}$. No obstante, el camino a seguir es avanzar y reducir exponencialmente las distorsiones producidas por una interpretación des-armonizada de las normas europeas ${ }^{20} \mathrm{y}$ de las normas aplicables al comercio marítimo interna-

${ }^{6}$ F. BerLINGIERI, “Uniformité du Droit Maritime. Quelques problems”, Il dir.mar, 1992-III, pp. 796 y ss.; sobre el particular vid. igualmente J. RAMBERG, "Unification of transport law: difficulties and possibilities", Dir.mar., 2010, pp. 813-818. En relación a la historia de las Reglas de Rotterdam, vid. F. BERLIngIERI, "The history of the Rotterdam Rules", The United nations Convention on Contracts for the International Carriage of goods Wholly or Partly by Sea-An Appraisal of the Rotterdam rules, M.D. Guner-Özbek (Ed.), Springer-Verlag, Berlin-Heiderberg, 2011, pp. 1-63.

7 J.L. Iriarte Ángel, "La armonización del Derecho internacional privado por la Unión Europea", Jado: Boletín de la Academia Vasca del Derecho, no 9, 2006, pp. 47-73

${ }^{8}$ En este sentido vid. A.L. Calvo Caravaca, "El Derecho internacional privado de la Comunidad Europea", Anales de Derecho, Universidad de Murcia, no 21, 2003, pp. 49-69.

9 J.J. Álvarez Rubio, "La incidencia del Tratado de Ámsterdam en el sistema español de Derecho interregional”, Anales de la Facultad de Derecho, 18, noviembre de 2001, pp. 65-78.

${ }^{10}$ Véase A. Borras Rodríguez, "La Comunitarización del Derecho Internacional Privado: pasado, presente y futuro", Cursos de Derecho Internacional de Vitoria-Gasteiz (2001), Vitoria-Gasteiz, Servicio de Publicaciones de la Universidad del País Vasco, 2002, pp. 285-318.

${ }^{11}$ A. Borras Rodríguez, "La proyección externa de la comunitarización del Derecho internacional privado: los datos del problema”, La Ley, núm. 5611, 2002, pp. 1-8.

${ }^{12}$ En este sentido vid: J.C. FernÁNDEZ Rozas, "La comunitarización del Derecho internacional privado y Derecho aplicable a las obligaciones contractuales", RES, $\mathrm{n}^{\mathrm{o}} 140,2009$, pp. $600 \mathrm{y}$ ss.

${ }^{13}$ Una realidad a la que se enfrenta hoy el legislador europeo. Sobre esta cuestión, entre otros: S. Moya IzQuiERDo, C. García Fernández y M. Troncoso Ferrer, "El posible impacto del Brexit en los contratos internacionales de ámbito europeo", Revista Aranzadi Unión Europea, núm. 12, 2016.

${ }^{14}$ M. GuZMÁn ZaPATER, “Cooperación civil y Tratado de Lisboa: ¿Cuánto hay de nuevo?”, La Ley, nº 7479, 2010, pp.713 y ss.

${ }^{15}$ Sobre la evolución jurídica en el espacio europeo del Derecho internacional, entre otros: P.A. DE Miguel Asensio, "Integración Europea y Derecho Internacional Privado", RDCE, vol. 2, 1997, pp. 413-445.

${ }^{16}$ Entre otros sobre jurisdicción, arbitraje y la aplicación del RBI bis en materia marítima por English High Court; S. BAUGHEN, Shipping Law, Seventh Edition, Routledge, Abingdon, 2019, pp. 356-368.

${ }^{17}$ En relación a la integración económica y el desarrollo de un nivel adecuado de coordinación jurídica puede verse entre otros estudios J.M. Gondra Romero, "Integración económica e integración jurídica en el marco de la Comunidad Económica Europea”, en García De Enterría, E., GonzÁlez Campos J.D., Muñoz Machado S., (Dirs.), Tratado de Derecho comunitario europeo, vol. I, Madrid, 1986, pp. 275-312.

18 J.C. FernÁndez RozAs, “El 60 aniversario de los Tratados de Roma: algo más que una simple celebración”, La Ley, 46, 2017, pp. $1-8$.

${ }_{19}$ Para una perspectiva general, entre otros: : J.C. FernÁndez Rozas, "El Espacio de libertad, seguridad y justicia consolidado por la Constitución Europea", La Ley, D-195, 2004, p. 16.

${ }^{20}$ En relación al Derecho comunitario/europeo del Milan, transporte en la UE, puede verse a F. MunARI, Il Diritto Comunitario dei Trasportti, Milan, Guiffrè Editore, 1996, pp. 50-117. 
ciona $^{21}$. Más si cabe teniendo en cuenta que parte de la doctrina mercantilista e internacional-privatista viene de un tiempo a esta parte reclamando la especificidad y autonomía científica propia o inherente a este ámbito de estudio, pues la disciplina del Derecho del transporte internacional (europeo y extraeuropeo) y nacional tiene suficiente entidad propia como para ser considerada autónoma respecto a las restantes disciplinas o áreas del Derecho.

7. El respeto y la garantía del axioma que representa la autonomía de la voluntad ${ }^{22}$ de las partes contractuales en este importante sector del Derecho del transporte ${ }^{23}$ y su proyección a modo de foro de competencia judicial internacional debe tenerse siempre presente al sopesar los distintos intereses que afloran y confluyen en la materia ${ }^{24}$. En efecto, la libertad y capacidad de las partes para determinar una cláusula atributiva de jurisdicción respecto a unos concretos órganos jurisdiccionales, representa un concepto básico del actual Derecho marítimo privado que hace gala de técnicas y singularidades características como pudiera ser una cláusula flotante de jurisdicción.

8. Otra conflictividad concreta que aflora en este importante sector, de ahí el intento de reversión de la situación actual por parte del/la legislador/a interno/a en la LNM, es la relacionada con la producción de efectos frente a terceros no parte del contrato de la cláusula de elección de foro teóricamente convenida entre remitente/cargador y porteador/transportista. Ante esta tesitura será necesario ponderar y valorar la efectividad que tendrá para el tercero destinatario de la carga la cláusula de jurisdicción invocada por el porteador frente a la interposición de una acción de reclamación, por pérdida total o parcial o deterioro de la mercancía, entablada por parte del adquirente.

9. Sin duda la pluralidad de aspectos que deben valorarse a la hora de concretar la norma de aplicación para la cuestión dentro de los diversos bloques normativos coexistentes es ciertamente amplia: sometimiento expreso o tácito a tribunal extranjero; prórroga y/o derogación de la competencia; validez del acuerdo atributivo desde la doble perspectiva formal y material; la oponibilidad de la cláusula de jurisdicción frente a terceros no parte en el contrato, las relaciones forum-ius y/o la restricción o minoración del juego de la libre autonomía de la voluntad de las partes ${ }^{25}$.

10. La relativamente reciente Ley de Navegación Marítima española acrecienta esta compleja, diversa y atomizada maraña normativa que en ocasiones proyecta discordantes respuestas jurídicolegales sobre una misma realidad contractual, y sin embargo este haz de soluciones diversas es propio e inherente a los distintos ámbitos o sectores que conforman un Derecho del comercio internacional compuesto de múltiples bloques normativos ${ }^{26}$.

\footnotetext{
${ }^{21}$ En relación a la tendencia hacia la uniformidad normativa internacional del Derecho marítimo mediante una profusión de textos convencionales: T. TREVES, "Il nuovo Dirittto del Mare e le Convenzioni Internazionali sulla protezione dell' ambiente marino", Dir Mar, 1999-1, pp. 219-231; S.M. CARBone, y F. MunARI, "Diritto internazionale e traffici marittimi: La codificazione internazionale della disciplina dei traffici marittimi ed il ruolo al riguardo riservato ai soggetti economici privati", Regole e organizzazione dei trasporti marittimi internazionali, Milán, Giuffrè Editore, 1990, pp. 7- 10.

${ }^{22}$ Respecto a la autonomía de la voluntad en el sector del transporte, entre otros: E. CAstellanos Ruiz, Autonomía de la voluntad y derecho uniforme en el transporte internacional, Granada, Editorial Comares, 1999, pp. 12-15

${ }^{23}$ M. Pichars, "L'évolution de la norme dans les transports", en Peru-Pirotte, L., Dupont-Legrand, B., y Landsweerdt, C. (Dirs.), Le Droit du transport dans tous ses états: réalités, enjeux et perspectives nationales, internationals et européennes, Bruselas, Larcier, 2012, pp. 17-48.

${ }^{24}$ Sobre la primacía del respeto por la libertad de contratación y autonomía de la voluntad en el ámbito del Derecho marítimo, J.J. Álvarez RuBio, “Competencia judicial internacional en el transporte internacional. Especial referencia al transporte marítimo", en J.M De Eizaguirre Bermejo, El Derecho del transporte marítimo internacional, I Jornada sobre Transporte Marítimo Europeo, aspectos mercantiles y jurisdiccionales, Donostia (20 y 21 de mayo de 1993), Escuela de Administración Marítima- Itsas Arduralaritzazko Eskola, p. 133.

${ }^{25}$ Sobre el particular, vid. la excelente reflexión de J.C. Fernández RozAS, "Alternativas e incertidumbres de las cláusulas de solución de controversias en la contratación marítima internacional", $C D T$, vol.10, n 2 , octubre 2018, pp. 333-375.

${ }^{26}$ Respecto a esta cuestión, aunque con otro enfoque, puede verse: U. BelintXon MARTín, "Prevención de riesgos laborales, transporte y derecho europeo: distorsiones de la realidad práctica”, La Ley Unión Europea, nº 73, 2019, pp. 1-19.
} 


\section{Derecho marítimo y acuerdos atributivos de jurisdicción}

11. Nuestra norma de producción interna normativiza en sus artículos 468 y 469 las especialidades procesales de jurisdicción y competencia para el sector marítimo regulando los criterios de atribución de la competencia judicial internacional y los requisitos de validez de las cláusulas de sumisión a concretos foros recogidos en los contratos de utilización de buque.

12. La validez de estas cláusulas sumisorias, contenidas asiduamente en conocimientos de embarque, pólizas de fletamento y/o contratos de transporte marítimo, queda condicionada según la LNM a que se hayan negociado de forma individual y separada como muestra del consentimiento de las partes involucradas.

13. También debe recordarse que la ley española recoge criterios de atribución de la competencia judicial internacional ante la ausencia de acuerdo atributivo de jurisdicción valido, posibilitando a la parte actora seleccionar, para dilucidar la correspondiente contienda surgida en la materialización de los contratos de utilización de buque, entre distintos foros objetivos (los tribunales del lugar del domicilio de la parte demandada ${ }^{27}$, lugar de celebración del contrato o puerto de origen o destino).

14. El preámbulo de la LNM advierte de forma clara su finalidad última respecto a los acuerdos de sumisión expresa al tratar de reducir exponencialmente la imposición en el tráfico marítimo de éstos sobre los terceros poseedores del conocimiento de embarque que se ven obligados a pleitear ante tribunales extranjeros, o ante instancias arbitrales internacionales, pese a no haber negociado la incorporación de tales cláusulas al conocimiento de embarque por referencia a una póliza de fletamento ${ }^{28}$.

15. No obstante, la realidad imperante en el sector refleja que en la mayor parte de los contratos de transporte y utilización de buque, en especial para el transporte de contenedores en buques de línea regular, la advertida y exigida negociación individual no acaece, pues en gran medida o los contratos son suscritos mediante intermediarios, o las condiciones y el clausulado contractual viene impuesto y delimitado por el transportista marítimo que entrega al remitente el contrato una vez cargada la mercancía en la bodega del buque.

16. Expuesto lo que antecede, también es necesario recordar que el criterio que inspira el vigente artículo 25 del RBI bis ${ }^{29}$ (antiguo artículo 17 del Convenio de Bruselas de $1968^{30}$ ) pretende una solución ponderada y respetuosa tanto con la protección de las partes ante cláusulas oscuras insertas en el contrato, como con el afán de eludir un anquilosado anhelo formalista que entumezca el normal desarrollo de las operaciones comerciales internacionales. En esencia, el citado precepto evidencia que la forma escrita no es la única materializable, siendo por tanto plenamente valido cualquier modo que se ajuste a los hábitos que las partes tengan establecidos o que deriven de los usos vigentes en el comercio internacional.

17. Cautivo de esta realidad jurídico normativa y de los usos generalizados y aceptados en el transporte marítimo internacional, nuestro máximo tribunal europeo viene consolidando mediante su

${ }^{27}$ Sobre el foro general del domicilio del demandado, pueden verse las consideraciones realizadas acerca del contrato de embarque internacional por: J.L. IRIARTE Ángel, El contrato de embarque internacional, Madrid, Beramar S.L., 1993, pp. 100 y ss.

${ }_{28}$ JJ. Álvarez Rubio, y U. Belintxon Martín, "La nueva Ley de Navegación Marítima desde la perspectiva del Derecho Internacional”, en Emparanza Sobejano A, y Martín Osante, J.M. (dirs.), Comentarios sobre la ley de navegación marítima, Madrid, Marcial Pons, 2015, pp. 807-831.

${ }^{29}$ Reglamento (UE) $\mathrm{n}^{\circ} 1215 / 2012$ del parlamento europeo y del consejo de 12 de diciembre de 2012 relativo a la competencia judicial, el reconocimiento y la ejecución de resoluciones judiciales en materia civil y mercantil. DOUE L 351/1 de 20 de diciembre de 2012.

${ }^{30}$ Sobre el espacio judicial europeo y el Convenio de Bruselas de 1968 puede verse el exhaustivo estudio de S.M. CARBONE, Lo spazio giudiziario europeo: La Convenzioni di Bruxelles e di Lugano, Turín, G. Giappichelli Editore, 1997, pp. 11 y ss. 
jurisprudencia un criterio hermenéutico flexible con los condicionantes de validez de las cláusulas de sumisión expresa. La interpretación mayoritaria de nuestros órganos jurisdiccionales ha convalidado la validez y vigencia para el tercero subrogado en la posición jurídica del remitente de la cláusula atributiva de jurisdicción contenida en anverso de un conocimiento de embarque sin necesidad de negociación individualizada, siempre y cuando eso sí, ésta sea perfectamente visible y meridianamente clara.

18. La interpretación por el TJUE de la remisión que la citada norma de la UE contiene respecto a los usos del comercio internacional, ha servido como criterio orientador de un sinfín de resoluciones judiciales de los juzgados y tribunales internos que conceden total eficacia a las cláusulas atributivas de jurisdicción incorporadas en los conocimientos de embarque en favor de tribunales extranjeros ${ }^{31}$.

19. Es evidente y constatable que la línea jurisprudencial mantenida por el TJUE ha permitido la consolidación de la presunción del consentimiento ofrecido por las partes a la cláusula atributiva de jurisdicción cuando tal conducta responde a los advertidos usos universalizados en el correspondiente sector comercial y conocido por las empresas operadoras. En efecto, cuando dichas operadoras concatenan un comportamiento o pauta determinada de manera asidua en la ejecución y materialización de este tipo de contratos de transporte marítimo internacional, en los que la inserción de cláusulas atributivas de jurisdicción es la nota habitual, la plena validez de dicho uso no exige mayor actividad probatoria siendo incontrovertida la existencia del consentimiento y el conocimiento por las partes a dicha cláusula lo que hace innecesaria una negociación individual y separada de tal cláusula contractual o acuerdo.

20. Tampoco debe descuidarse que esta introspección se focaliza sobre el sector del transporte marítimo internacional, con unas predilecciones e intereses muy particulares inherentes al ámbito del Derecho del transporte internacional, en el que impera el juego de la autonomía de la voluntad de las partes y una práctica y unos usos comerciales asentados y seguidos por las empresas operadoras de tal forma que aporten a la seguridad jurídica y a la previsibilidad de resultado.

21. Sin duda es obligada una reflexión sosegada sobre cada uno de los intereses en presencia con la única y exclusiva finalidad de no desatender otros no menos legítimos encarnados por los terceros poseedores del conocimiento de embarque o documento similar (como la carta de porte marítima) y que a priori quedan ajenos a la originaria relación contractual, pero que sin embargo deben ser atendidos con el objetivo de reducir exponencialmente potenciales vulneraciones de sus derechos, quedando sujetos a tener que litigar en terceros países extraños y/o lejanos cuando con total seguridad no han podido tener constancia ni aceptar de forma previa tal acuerdo de sumisión expresa.

22. De esta manera, la apreciación de la referida aceptación se erige clave para evaluar y/o estimar la validez de tal cláusula o acuerdo. La nuclear importancia que ostenta esta praxis en relación tanto a las cláusulas arbitrales como a las cláusulas jurisdiccionales ordinarias, evidencia la necesidad de atender concretamente esta cuestión más si cabe ante la regulación restrictiva de nuestra LNM que desatiende lo articulado por las normas internacionales en vigor ${ }^{32}$.

23. En efecto, la lectura literal del artículo 468 de la referida Ley de Navegación Marítima española sugiere la inversión de la presunción de validez de las cláusulas de sumisión expresa recogidas en documentos generalizados de la práctica del denominado Derecho de los formularios, al indicar expresamente que sin perjuicio de lo previsto en los convenios internacionales vigentes en España y en

\footnotetext{
${ }^{31}$ En relación a la interpretación del TJUE sobre las cláusulas de foro insertas en un conocimiento de embarque y los usos del comercio internacional, entre otros: E. Torralba Mendiola, "Las «especialidades procesales» de la Ley de Navegación Marítima: cláusulas de jurisdicción y arbitraje”, $R D T, \mathrm{n}^{\circ} 16,2015$, pp. 121-131.

${ }^{32}$ Sobre la prioritaria aplicación del Derecho Uniforme frente al Derecho interno, puede verse el clarificador estudio de J.M. RUIZ SOROA, "El Derecho Uniforme en la Ley de Navegación Marítima", en Emparanza Sobejano A, y martín osante, J.M. (dirs), Comentarios sobre la ley de navegación maritima, Marcial Pons, Madrid, 2015, pp. 49-60.
} 
las normas de la Unión Europea, serán nulas y se tendrán por no puestas las cláusulas de sumisión a una jurisdicción extranjera o arbitraje en el extranjero, contenidas en los contratos de utilización del buque o en los contratos auxiliares de la navegación, cuando no hayan sido negociadas individual y separadamente. En particular, la inserción de una cláusula de jurisdicción o arbitraje en el condicionado impreso de cualquiera de los contratos a los que se refiere el párrafo anterior no evidenciará, por sí sola, el cumplimiento de los requisitos exigidos en el mismo.

24. Pretende la persona legisladora con la normativización de esta cuestión proteger los intereses de los terceros (empresas destinatarias u otras usuarias) extraños a la originaria relación contractual o con estrecho margen en la negociación para los contratos de utilización de buque.

25. La puesta en práctica y aplicación de este artículo normativo está siendo controvertido y está requiriendo de los juzgados y tribunales internos una especial sensibilidad y capacidad para concretar y determinar, caso por caso, el principio de usos del comercio internacional, cuestión que en ocasiones, según se puede apreciar de la jurisprudencia interna existente, se está tornando, interesada o desinteresadamente, en algo ciertamente complejo, pues a pesar de puntuales intentos jurisprudenciales una interpretación flexible en cuanto a la validez de las cláusulas sumisorias es necesaria en el sector marítimo internacional. Lo contrario, es decir la aplicación por nuestros juzgados y tribunales del criterio restrictivo proyectado por la LNM de exigir una negociación individual y separada de las cláusulas jurisdiccionales, genera distorsiones que acaban aflorando incertidumbres en cuanto a la seguridad jurídica y la previsibilidad de resultado, en un sector que requiere de un alto dinamismo en sus operaciones con la finalidad de ser efectivos en términos comerciales ${ }^{33}$.

26. Los artículos 468 y 469 de la LNM normativizan ciertas especialidades de jurisdicción y competencia que se centran en regular la eficacia y los requisitos de los acuerdos atributivos de jurisdicción y en articular una suerte de foros objetivos alternativos a elección del demandante ${ }^{34}$. De la lectura del artículo 468 se advierte, pero debe subrayarse, que la disposición no se dedica a la atribución de competencia judicial a los juzgados y tribunales españoles, sino que concreta sus esfuerzos en el análisis de la validez de las cláusulas de sumisión expresa a órganos jurisdiccionales o arbitrales extranjeros. En efecto, esto significa que la LNM únicamente proyectará su operatividad y aplicación respecto a la derogatio fori de la competencia de los órganos jurisdiccionales españoles ante la inaplicación según la regla de la especificidad de un convenio internacional o el RBI bis ${ }^{35}$.

27. Lo anterior nos lleva a tener que concretar que acaece una evidente disociación entre lo que dispone el comentado artículo 468 de la norma de navegación marítima española, mucho más restrictiva sobre la eficacia derogatoria de los acuerdos atributivos de jurisdicción o competencia que designen como competentes a juzgados o tribunales extranjeros, y lo regulado por el artículo 25 del RBI bis ${ }^{36}$. Expuesto ello, debe subrayarse con claridad meridiana que ante un conflicto sobre la aplicación prioritaria de lo dispuesto en la norma europea de aplicación directa y lo dispuesto en la LNM prevalecerá, sin

${ }^{33}$ Véase entre otros: A. Von ZIEGLER. "Alternatives and Methods of Unification or Harmonization of Maritime Law”, Dir Mar, vol.101, nº 1, 1999, pp. 232-239.

${ }^{34}$ El artículo 468 LNM dispone que: "Sin perjuicio de lo previsto en los convenios internacionales vigentes en España y en las normas de la Unión Europea, serán nulas y se tendrán por no puestas las cláusulas de sumisión a una jurisdicción extranjera contenidas en los contratos de utilización del buque o en los contratos auxiliares de la navegación, cuando no hayan sido negociadas individual y separadamente. En particular, la inserción de una cláusula de jurisdicción o arbitraje en el condicionado impreso de cualquiera de los contratos a los que se refiere el párrafo anterior no evidenciará, por sí sola, el cumplimiento de los requisitos exigidos en el mismo".

${ }^{35}$ Para el estudio de las normas del RBI bis sobre competencia judicial internacional aplicables a este sector, entre otros: A. HERNÁNDEZ RoDRíGUEZ, "El contrato de transporte aéreo de pasajeros: algunas cuestiones sobre competencia judicial internacional y derecho aplicable", $C D T$, vol.3, n $^{\circ} .1$, marzo 2011, pp. 179-194.

${ }^{36}$ Sobre dicha cuestión, entre otros: J. Del CoRTE, "Especialidades procesales en la Ley de Navegación Marítima", en EMparanza Sobejano A, y Martín Osante, J.M. (dirs), Comentarios sobre la ley de navegación marítima, Madrid, Marcial Pons, 2015, pp. 753-768. 
atisbo de duda, lo dispuesto por el/la legislador/a europeo/a en el RBI bis siempre y cuando la jurisdicción extranjera designada como competente para conocer esté en un Estado parte de la Unión Europea.

28. Una lectura en sentido contrario a lo dispuesto que priorizase lo normativizado por la LNM mediante flagrante vulneración de la regla de especialidad conllevaría que la eventual o hipotética resolución española de un órgano jurisdiccional, que asume su competencia al existir un acuerdo atributivo de jurisdicción que no ha sido negociado de forma individual o separada pero que si forma parte y está nítidamente indicada en el contrato marítimo (valórese el modelo estándar dispuesto por el artículo 67.1 de las Reglas de Rotterdam ${ }^{37}$ ), careciese de eficacia en el extranjero en sede de reconocimiento y ejecución.

29. En esencia, tal y como se advierte, debido a la singularidad inherente a la disciplina del Derecho marítimo y muy especialmente al sector del transporte marítimo de mercancías en sus distintas modalidades (internacional, nacional y cabotaje), el nuclear posicionamiento de los usos, costumbres y prácticas comerciales marítimas han facilitado una interpretación flexible por parte del TJUE de la cláusulas de foro, extensible en similar medida a las cláusulas arbitrales, facilitando con ello el desarrollo dinámico de las operaciones comerciales en el sector.

30. El consciente descuido del/la legislador/a interno/a de este principio o elemento clave en la redacción de la LNM, y la inatención de las soluciones previstas y los condicionantes de validez de las cláusulas de sumisión expresa recogidas en el RBI bis no hace sino complicar todo el elenco de intereses en presencia junto a la minoración de los estándares europeos ${ }^{38}$ en materia de seguridad jurídica, previsibilidad de resultado, confianza recíproca en el seno de la justicia en la UE y la evitación de procedimientos paralelos.

31. La norma española como advertimos normativiza singulares especialidades en materia de competencia judicial internacional al tratar combinada, pero separadamente, las normas de aplicación a las cláusulas de jurisdicción y arbitraje (artículo $468^{39}$ ) y los criterios de atribución de competencia y foros objetivos alternativos a elección de la parte demandante (artículo $469^{40}$ ).

${ }^{37}$ Artículo 67 Acuerdos de elección de foro: 1. La competencia de un tribunal designado con arreglo al apartado b) del artículo 66 sólo será exclusiva respecto de las controversias entre las partes en el contrato si éstas así lo han pactado y el acuerdo que reconozca dicha competencia: a) Forma parte de un contrato de volumen en el que están claramente indicados los nombres y las direcciones de las partes y que o bien: i) ha sido individualmente negociado, o bien ii) advierte de manera visible de la existencia de un acuerdo exclusivo de elección de foro, con especificación de las cláusulas o secciones del contrato de volumen que lo incluyen; y b) Designa con claridad a los tribunales de un Estado Contratante, o a uno o más tribunales específicos de un Estado Contratante. 2. Una persona que no sea parte en el contrato de volumen sólo quedará vinculada por un acuerdo exclusivo de elección de foro concertado con arreglo al párrafo 1 del presente artículo cuando: a) El tribunal elegido esté situado en alguno de los lugares indicados en el apartado a) del artículo 66; b) El acuerdo figure en el documento de transporte o en el documento electrónico de transporte; c) Dicha persona haya sido adecuada y oportunamente informada sobre cuál es el tribunal ante el que debe entablarse la acción y sobre el carácter exclusivo de su competencia al respecto; y d) La ley del tribunal que conozca del caso prevea que dicha persona puede quedar obligada por un acuerdo exclusivo de elección de foro.

${ }^{38}$ Respecto a los estándares europeos referidos, aunque para el ámbito del desplazamiento transfronterizo de trabajos veasé el excelente estudio de la maestra y profesora M. CASAdo Abarquero, "Legislación aplicable a los trabajadores desplazados en el marco de una prestación de servicios en la Unión Europea", en GoÑ Sein, J.L, e Iriarte Ángel, J.L. (Dirs), Prevención de riesgos laborales y protección social de trabajadores expatriados, Cizur Menor, Thomson Reuters Aranzadi, 2019, pp. 339-369

${ }^{39}$ Artículo 468 Cláusulas de jurisdicción y arbitraje: Sin perjuicio de lo previsto en los convenios internacionales vigentes en España y en las normas de la Unión Europea, serán nulas y se tendrán por no puestas las cláusulas de sumisión a una jurisdicción extranjera o arbitraje en el extranjero, contenidas en los contratos de utilización del buque o en los contratos auxiliares de la navegación, cuando no hayan sido negociadas individual y separadamente. En particular, la inserción de una cláusula de jurisdicción o arbitraje en el condicionado impreso de cualquiera de los contratos a los que se refiere el párrafo anterior no evidenciará, por sí sola, el cumplimiento de los requisitos exigidos en el mismo.

${ }^{40}$ Artículo 469 Criterios de atribución de competencia: 1. Salvo que las partes hayan introducido válidamente una cláusula de jurisdicción exclusiva o una cláusula de arbitraje, según lo establecido en este capítulo, se aplicarán los criterios previstos en este artículo. 2. En los contratos de utilización del buque, serán competentes, a elección del demandante, los tribunales del: a) Domicilio del demandado. b) Lugar de celebración del contrato. c) Puerto de carga o descarga. 3. En los contratos auxiliares de la navegación, serán competentes, a elección del demandante, los Tribunales del: a) Domicilio del demandado. b) Lugar de celebración del contrato. c) Lugar de prestación de los servicios.4. Para conocer de la impugnación de la liquidación de 
32. Se ha apuntado anteriormente que el 468 de la LNM articula una norma sobre los acuerdos atributivos de jurisdicción o cláusulas de sumisión expresa que claudica ante la existencia de Convenios internacionales especiales que fuesen de aplicación, y en ausencia de éstos, será igualmente relegada por lo dispuesto en el RBI bis sobre la prorrogatio fori (artículo 25) ${ }^{41}$.

33. Este precepto europeo posibilita a las partes sin importar la localización de su domicilio, pactar someter sus contiendas a los órganos jurisdiccionales de un Estado miembro de la Unión Europea $^{42}$. Proyectable esto sobre el sector marítimo internacional significa que una cláusula atributiva de jurisdicción en un contrato auxiliar de la navegación o un contrato de utilización de buque ${ }^{43}$ que designe como competente a un juzgado o tribunal de un Estado de la UE, quedará regulada respecto a su validez por el citado artículo $25^{44}$. Este precepto también recoge otros aspectos de nuclear importancia, como la concreción como ley rectora para comprobar la validez material de los acuerdos atributivos de jurisdicción de la ley del Estado escogido como competente para conocer de la disputa. También se recoge por el mencionado artículo la autonomía de los acuerdos de sumisión expresa respecto al resto de cláusulas contractuales ${ }^{45}$.

34. No obstante como indicamos, la LNM en su artículo 468 alberga una redacción e interpretación restrictiva y a sensu contrario de la norma europea respecto a la eficacia de la derogación de la competencia de los órganos jurisdiccionales españoles ante la presencia de acuerdo de sumisión expresa en favor de órgano jurisdiccional extranjero o tribunal arbitral extranjero, promulgando la nulidad de toda cláusula o acuerdo que no se haya negociado de una manera individual y separada al contrato de transporte marítimo ${ }^{46}$. Esto conlleva, para los supuestos en los que los órganos jurisdiccionales extranjeros designados como competentes no estén erradicados en un Estado de la Unión Europea o no sean parte de un Convenio internacional vigente que regule la cuestión en el ordenamiento jurídico español, que será de aplicación lo dispuesto por el articulado analizado de la LNM que promulga la nulidad de toda cláusula sumisoria de jurisdicción (contratos auxiliares de la navegación y/o contratos de utilización de buque) que no cumpla con los condicionantes impuestos en dicha ley.

35. Ante esta serie de supuestos, y para los contratos auxiliares de la navegación y contratos de utilización de buque, la asunción de competencia por parte de los órganos jurisdiccionales españoles vendría concretada por los foros objetivos alternativos elegibles por la parte actora regulados en el citado artículo 469 LNM. Es decir: domicilio de la parte demandada; lugar de celebración del contrato; y/o puerto de origen o destino del transporte marítimo de mercancías. Desde luego, tal incomprensible criterio contrario a los tiempos actuales únicamente tiene cabida en una lectura o interpretación con-

avería gruesa, tanto la efectuada privadamente como la realizada por un notario con arreglo al correspondiente expediente de certificación pública, será competente el tribunal del lugar de finalización del transporte o el del lugar de arribada del buque, si este último fuese distinto.

${ }^{41}$ En relación a la prorrogatio fori y derogatio fori entre otros, F.F. GARAU SoBrino, "Los acuerdos atributivos de jurisdicción en Derecho procesal civil internacional español", $C D T$, vol. 2, nº 2, Octubre 2010, pp. 53 y ss.

${ }^{42}$ Sobre tal cuestión, vid. P.A. De Miguel Asensio, "El nuevo Reglamento sobre competencia judicial y reconocimiento y ejecución de resoluciones", La Ley, XXXIV, n 8013, 2013, pp. 1-4; A.P. ABARCA JunCo (Dir.), "La competencia judicial de los tribunales españoles: Foro de la autonomía de la voluntad", Derecho Internacional Privado, Madrid, UNED, 2013, pp. 134 y ss.

${ }^{43}$ Sobre los contratos de utilización de buque, entre otros: A. Recalde Castells, "Los contratos de utilización del buque", en Emparanza Sobejano, A. y Martín Osante, J.M., Estudio Sistemático de la Propuesta de Anteproyecto de Ley General de la Navegación Marítima, Gobierno Vasco, Dpto. de Transporte y Obras Públicas, 2006, pp. 253-287.

${ }^{44}$ En relación a los acuerdos atributivos de jurisdicción y las potencialidades del artículo 25 del RBI bis, entre otros, aunque en referencia al sector del transporte aéreo internacional de mercancías: U. BELINTXON MARTín, "Derecho internacional privado y transporte aéreo: cuestiones de actualidad sobre jurisdicción y ley aplicable”, en Petit Lavall, M.V., y Puetz, A. (Dirs.): El transporte como motor del desarrollo socioeconómico, Madrid, Marcial Pons, 2018, pp. 363-382.

${ }^{45}$ Artículo 25.5 RBI bis: "Un acuerdo atributivo de competencia que forme parte de un contrato será considerado como un acuerdo independiente de las demás cláusulas del contrato. La validez del acuerdo atributivo de competencia no podrá ser impugnada por la sola razón de la invalidez del contrato".

${ }^{46}$ Véase P.A. De Miguel Asensio, "Los acuerdos de jurisdicción en la nueva Ley de Navegación Marítima”, de 17 de septiembre de 2014, (Recuperado de: http//:pedromiguelasensio.blogspot.com.es /2014/10/ los-acuerdos-de-jurisdicción-en-la-lnm). 
traria a la realidad sectorial que responde a tiempos ya superados en los que imperaba una perspectiva de nacionalismo jurídico-legislativo sin cabida en el actual siglo XXI y que sería correspondida en la esfera europea, e internacional, con la ausencia de efectos en el ámbito de la validez extraterritorial de la correspondiente resolución ${ }^{47}$.

36. Todo ello sin obviar que pudieran aflorar procedimientos paralelos sobre el mismo objeto de controversia al aceptar su competencia, según acuerdo atributivo de jurisdicción, el órgano jurisdiccional extranjero y asumir también los juzgados o tribunales españoles el asunto en aplicación de los foros objetivos alternativos. Desde luego, en la esfera europea e internacional la asunción de competencia por parte de los juzgados y tribunales españoles sería considerada como exorbitante en fase de reconocimiento y ejecución y por lo tanto como claudicante cualquier resolución emitida por los órganos jurisdiccionales patrios. Lógicamente, por otro lado, debemos entrever que ante la citada tesitura los órganos jurisdiccionales españoles corresponderían de la misma manera en fase de reconocimiento y ejecución ante cualquier resolución del órgano jurisdiccional extranjero designado como competente según el acuerdo de sumisión expresa ${ }^{48}$. Es decir, que afloran claras incertidumbres en materia de litispendencia y conexidad generadas por la interpretación restrictiva de la norma nacional ${ }^{49}$.

37. En esencia debe remarcarse que lo normativizado sobre la cuestión por la LNM restringe el juego de la autonomía de la voluntad de las partes para la designación de la jurisdicción competente contraviniendo la imperante realidad actual en un sector que reclama, por su dinamismo, el objetivo de seguridad jurídica mediante normas claras de compatibilidad entre las diversas normas coexistentes y siempre con el máximo de los respetos a la regla de especialidad contenida en las normas europeas y refrendada por el TJUE en su jurisprudencia ${ }^{50}$.

38. El ejercicio legislativo de carácter restrictivo realizado en la LNM para el capítulo dedicado a las especialidades de jurisdicción y competencia ha pretendido, según el propio preámbulo de la norma y siempre con el máximo respeto a la aplicación preferente de las normas contenidas en los Convenios internacionales ${ }^{51} \mathrm{y}$ en el Derecho de la UE, evitar los abusos detectados declarando la nulidad de la cláusulas de sumisión a una jurisdicción extranjera o a arbitraje en el extranjero, contenidas en los contratos de utilización del buque o en los contratos auxiliares de navegación, cuando no hayan sido negociadas individual y separadamente. Eso sí, como advertimos, de forma poco sensible, de dudosa proyección fuera de nuestras fronteras y alejada de una realidad comercial marítima internacional que pivota en materia de acuerdos atributivos de jurisdicción sobre los hábitos de las partes y los usos del sector ${ }^{52}$.

39. El sentido opuesto al avance del estado de las cosas de esta restrictiva actuación legislativa ha sido evidenciado por parte de la doctrina al valorar el alejamiento de la LNM respecto a la orientación esgrimida y proyectada por el Convenio de la Haya de 30 de junio de 2005 sobre acuerdos de elección de foro ${ }^{53}$.

${ }^{47}$ M. Gómez Gene, "Las cláusulas de jurisdicción y arbitraje en la nueva ley de navegación marítima”, Cuad.Der.Trans., vol. $6, \mathrm{n}^{\circ} 2$, Octubre 2014, pp. 118 y ss.

${ }^{48}$ Sobre este particular, J.M. GonzÁlez Pellicer, "Sobre el artículo 468 del Proyecto de Navegación Marítima y la nulidad de las cláusulas de elección de foro en los conocimientos de embarque”, La Ley, no 8354, Sección Doctrina, 15 de julio de 2014 , Año XXXV, pp. 8 y ss.

${ }^{49}$ Respecto a la litispendencia y conexidad internacionales puede verse M. Virgós Soriano y F.J. Garcimartín Alférez, Derecho Procesal Civil Internacional. Litigación internacional, Pamplona, Thomson-Civitas, 2007, pp. 362-381.

${ }^{50}$ Entre otras: STJUE de 4 de mayo de 2010, Asunto C-533/08 y STJUE de 19 de diciembre de 2013, Asunto C-452/12. Aranzadi.

${ }^{51}$ P. IVALDI, Diritto Uniforme dei trasporti e Diritto internazionale privato, Milan, Guiffrè, 1990, pp. 1-45.

52 J.J. Álvarez Rubio, "Transporte Marítimo Internacional de Mercancías: alcance material y conflictual de la Autonomía contractual”, AEDIPR., t. VIII, 2008, pp. 558-559.

${ }^{53}$ A. ZuRimendi IsLA, "Las cláusulas de jurisdicción y arbitraje incluidas en el conocimiento de embarque tras la Ley de Navegación Marítima”, RDT, $\mathrm{n}^{\circ}$ 18, 2016, pp. 89-110. 
Dicha norma internacional de un interés científico-practico indudable ${ }^{54}$ sobre los acuerdos exclusivos de elección de foro y posible aplicación a los contratos de gestión naval, consignación de buques, practicaje ${ }^{55}$ y manipulación portuaria, todos ellos contratos auxiliares a la navegación ${ }^{56}$, no se tiene en cuenta ni se respeta por la norma nacional contraviniendo una vez más la regla de la especificidad en materia de aplicación preferente de los Convenios internacionales y las normas europeas ${ }^{57}$.

40. Por el momento, es necesario subrayar el reducido iter práctico-procesal que las previsiones contenidas en los artículos 468 y 469 de la ley española están teniendo sobre los contratos auxiliares de la navegación de carácter internacional, aunque existen ciertas salvedades e intentos a sensu contrario. En efecto, nos referimos a los casos en los que los órganos jurisdiccionales extranjeros designados por las partes mediante cláusulas de sumisión expresa no estén ubicados en Estados en los que es de aplicación el RBI bis o un Convenio internacional que regule esta opción procesal y del que forma parte España.

41. La consolidación de usos concretos y especializados en el ámbito marítimo internacional se ha dado de forma gradual y continua y tienen hoy un influjo determinante en la dilución de las contiendas marítimas tanto en la concreción del órgano jurisdiccional competente como en la determinación de la ley de aplicación a éstas ${ }^{58}$. Dichos usos son los que precisamente están consolidando una flexible interpretación de los condicionantes formales y materiales de las cláusulas de elección de foro y favorecen con ello una relajación sobre el cumplimiento de los citados condicionantes para favorecer un dinámico desarrollo comercial $^{59}$. No obstante, la norma interna española plantea una interpretación limitativa o restrictiva compatible única y exclusivamente en la relación entre remitente y transportista marítimo, descartando la posibilidad de extrapolar o ampliar la operatividad de dichas cláusulas más allá de la relación original y proyectarla sobre terceros interesados, por ejemplo la empresa o persona destinataria de las mercancías que debe conocer los usos de un sector comercial en el que es habitual la concreción o inserción de cláusulas atributivas de jurisdicción en los conocimientos de embarque.

42. Claro está, estamos hablando de que se presume en el citado sector comercial internacional el conocimiento y aceptación de dichos usos por terceros interesados quedando totalmente justificada la validez formal y material de la cláusula jurisdiccional o arbitral incorporada, desterrando o desplazando el argumento de indefensión de la figura del tercero interesado en la mercancía transportada.

${ }^{54}$ Respecto a esta norma de carácter doble, pues regula tanto la competencia judicial internacional como el reconocimiento y ejecución de decisiones, entre otros puede verse: R. ARENAS García, "La aprobación por la UE del Convenio de La Haya sobre acuerdos de elección de foro: un cruce de caminos", La Ley, n²2, enero de 2015, pp. 35-45.

${ }_{55}$ Sobre el contrato de practicaje como contrato auxiliar de la navegación marítima, véase el excelente trabajo del amigo y profesor, I. ZurutuZa Arigita, El practicaje, Madrid, Marcial Pons, 2013, pp. 176-181.

56 Puede verse sobre los contratos auxiliares de la navegación entre otros, F.C. LóPEZ RuEDA, "De los contratos auxiliares de la navegación", en Emparanza Sobejano A. (Dir.): Estudio sistemático de la Propuesta de Anteproyecto de Ley General de la Navegación Marítima, Vitoria-Gasteiz, Servicio Central de Publicaciones del Gobierno Vasco, 2006, pp. 415- 479;

57 T. Harley, y M. Dogauchi, Informe explicativo del Convenio de 30 de junio de 2005 sobre Acuerdos de Elección de Foro, Texto adoptado durante la Vigésima Sesión, Editado por la oficina permanente de la Conferencia. (Recuperado de: $w w w$. hcch.net/upload/expl37s.pdf).

${ }^{58}$ En relación al Reglamento Roma I y su aplicación, entre otros puede verse, aunque enmarcado en la determinación de la ley aplicable en materia de prevención de riesgos laborales, J.L. IRIARTE ÁngEL, "La ley aplicable al contrato de trabajo internacional desde la perspectiva de la prevención de riesgos laborales en el caso del trabajador desplazado en el extranjero", en Goñi Seín, J.L. y Iriarte Ángel, J.L., Prevención de riesgos laborales y protección social de trabajadores expatriados, Cizur Menor, Aranzadi-Thomson Reuters, 2019, pp. 267-301.

${ }^{59}$ Sobre este particular entre otros: P.A. De Miguel Asensio, "Contratación internacional: La evolución del modelo de la Unión Europea”, Revista mexicana de Derecho internacional privado y comparado, nº 29, septiembre de 2011, pp. 67-89. 


\section{Competencia judicial internacional y acuerdos atributivos de jurisdicción en LNM. Solucio- nes de nuestros tribunales}

\section{Acuerdo atributivo de jurisdicción inserto en conocimiento de embarque y prevalencia del artí- culo 25 RBI bis sobre el artículo 468 LNM}

43. El posicionamiento de nuestros tribunales en esta materia está siendo por el momento mayoritariamente acertada y respetuosa con el Derecho de la UE, no obstante, debe advertirse la existencia de determinados pronunciamientos en sentido contrario. Muy acertadamente, entre otras, la Audiencia Provincial de Valencia en su auto de 8 de noviembre de $2016^{60}$ ante un supuesto en el que existe un sometimiento expreso de las partes incorporado mediante cláusula de sumisión en el conocimiento de embarque al Tribunal Superior de Justicia de Londres y un acuerdo de ley aplicable a la legislación británica, y teniendo en consideración el marco normativo y jurisprudencial aplicable para la determinación de la competencia judicial internacional compuesto por la LNM (artículo 468) y el RBI bis (artículo 25), viene a concretar que la actora, en su calidad de cargadora es parte en el contrato y queda por tanto vinculada por su contenido, aun cuando la relación con la naviera se materializase mediante un comisionista, a quien le fue encomendada la intermediación en el contrato de transporte marítimo y quien contrató por cuenta y nombre del comitente quedando reflejado todo ello en el citado conocimiento de embarque al constar este último como cargador y por lo tanto vinculado por la cláusula de jurisdicción.

44. A pesar de los intentos de la recurrente por revertir el fallo de instancia en el que se estima la declinatoria interpuesta por la parte demandada (incluso trayendo a colación los artículos 66 y 67 de la Reglas de Rotterdam sobre jurisdicción y acuerdos de elección de foro no aplicables por no encontrarse en vigor el citado texto internacional), la Audiencia proyecta en su resolución un razonamiento jurídico tercero (párrafos 13,14 y 15 ) ciertamente clarificador al concretar muy acertadamente que [...] el debate jurídico no se sitúa en ese tramo de la cadena de rangos normativos (uso vs. norma legal), sino en un tramo superior (normativa nacional vs. normativa comunitaria), pues como dispone el propio artículo 468 de la LNM, su aplicación opera sin perjuicio de lo previsto en los convenios internacionales vigentes en España y en las normas de la Unión Europea [...].

45. En efecto, es el Derecho europeo de la Unión Europea el rango normativo que resulta de aplicación a esta resolución ( $\mathrm{y}$ en la correspondiente de instancia), pues la existencia de un acuerdo de sumisión a los tribunales de un Estado miembro de la UE (ya que sigue por el momento, como advertimos, siendo de aplicación el RBI bis al Reino Unido con independencia de las consecuencias que de ello puedan aflorar en el futuro y respecto al régimen de fuentes aplicables frente a las cláusulas atributivas de jurisdicción a los tribunales ingleses) se normativiza mediante el artículo 25 del RBI bis en detrimento de las normas de origen interno.

46. En similares términos, y también muy acertadamente, se pronuncia sobre esta cuestión la Audiencia Provincial de Pontevedra en su auto de 16 de octubre de $2017^{61}$ y con claridad meridiana recoge una clara distinción entre Foro e Ius para clarificar a la recurrente que estamos ante una cuestión incardinada en el marco de una declinatoria internacional en relación a una cláusula de jurisdicción incorporada en un conocimiento de embarque para un envío de langostinos por vía marítima. Y en consecuencia desestima el recurso interpuesto en aplicación de la regla de la especialidad o especificidad contenida en el propio artículo 71 del RBI bis ${ }^{62}$.

\footnotetext{
${ }^{60}$ AAP de Valencia (Sección 9a, Civil), de 8 de noviembre de 2016, Aranzadi. JUR /2017/14921.

${ }^{61}$ AAP de Pontevedra (Sección 1 ${ }^{\text {a }}$, Civil), de 16 de octubre de 2017, Aranzadi. AC/2018/201.

${ }^{62}$ Artículo 71.1: 1. El presente Reglamento no afectará a los convenios en que los Estados miembros sean parte y que, en materias particulares, regulen la competencia judicial, el reconocimiento o la ejecución de las resoluciones.
} 
47. Así en el párrafo 15 de su fundamento de derecho segundo recoge la resolución que [...] en relación con la oponibilidad de la cláusula de jurisdicción inserta en el conocimiento de embarque a terceros que no fueron parte en el contrato original entre el cargador y el porteador marítimo, hemos entendido como indiscutible que la cláusula por la que se defiere la jurisdicción a los tribunales de otros Estado puede ser opuesta por el transportista marítimo más allá del ámbito subjetivo en el que se establece el contrato de transporte, en particular al destinatario final de las mercancías, aunque éste no estampara su firma en el documento contractual [...]. La cuestión debe resolverse en aplicación del art.25 del Reglamento Bruselas I bis, que desplaza a la norma interna. Por este motivo no nos parecen convincentes los argumentos del recurso que razonan sobre la base del art.468 de la LNM.

48. También acertadamente, la Audiencia Provincial de Barcelona en su Auto de 13 de febrero de $2019^{63}$ se posiciona en este sentido al estimar válida la cláusula de jurisdicción a los tribunales ingleses consciente de que los tribunales de Nueva York pudieran haber asumido la competencia si el lugar de origen o el lugar de destino hubiera estado ubicado allí ${ }^{64}$. El auto declara la ausencia de competencia judicial internacional de los tribunales españoles para conocer de la causa debido a la existencia del pacto de sumisión referenciado. La actora Aliments del Mar Ultracongelats, S.A reclama a la demandada, Mediterranean Shipping Company España S.L.U, el abono de los daños y perjuicios ocasionados por la pérdida de una partida de langostinos desde Mar de Plata a Barcelona y Vigo. Un transporte marítimo internacional que se ejecutó en régimen de conocimiento de embarque.

49. La Sala procede a realizar un análisis doble sobre las normas de jurisdicción normativizadas en la LNM y la regla de especialidad ${ }^{65}$ para determinar la prevalencia en la interacción de normas de los distintos bloques normativos en presencia (internacional, $\mathrm{UE}^{66}$, y nacional) ${ }^{67}$. De esta manera el tribunal manifiesta inequívocamente la aplicación prioritaria del artículo 25 del RBI bis sobre la norma española de aplicación. Un precepto que tal y como indicó en su resolución la Audiencia de Barcelona "establece cómo debe celebrarse el acuerdo atributivo de competencia y fija la Ley conforme a la cuál debe examinarse la validez del acuerdo (la del Estado Miembro a cuyos tribunales se hayan sometido las partes) (...). Por todo ello, dado que el contrato de transporte se suscribió entre las partes litigantes, únicas a las que se refieren los conocimientos de embarque, la aplicación del mencionado artículo 25 del Reglamento CE 1215 resulta procedente y ajustada a derecho la resolución recurrida".

50. Como bien es sabido, los citados bloques normativos ${ }^{68}$ vienen compuestos para esta especial materia por la LNM, el marco jurídico internacional convencional compuesto por el Convenio de Bruselas de 1924 en materia de conocimiento ${ }^{69}$, enmendado por el Protocolo de Bruselas de 23 de febrero de 1968 y el Protocolo de Bruselas de 1979 (sistema de "Las Reglas de La Haya” y "La Haya Visby")70, el Convenio de Hamburgo de 1978 sobre transporte marítimo de mercancías, las previsiones normati-

\footnotetext{
${ }^{63}$ AAP de Barcelona (Sección 15. Civil), de 13 de febrero de 2019, CENDOJ. ECLI: ES: APB: 2019:395.

${ }^{64}$ Sobre ello, J.J. ÁlvAREz RuBio, "Una acertada orientación jurisprudencial en relación a la validez y alcance de la cláusula sumisoria a favor de tribunal extranjero contenida en un conocimiento de embarque. Comentario al auto de 13 de febrero de 2019 de la AAP de Barcelona (Sección 15)”, CDT, vol.11, n 2, 2019, pp. 388-401.

${ }^{65}$ F.F. Garau Sobrino, "La literalidad interpretada desde la coherencia del sistema. Las relaciones entre Reglamento Bruselas I y los convenios sobre materias particulares según el TJUE”, CDT, vol. 3, nº1, 2011, pp. 270-281.

${ }^{66}$ Véase sobre la importancia del Derecho europeo y su incidencia sobre el sistema español de Derecho internacional privado entre otros: M. Desantes ReAL, "La incidencia de las fuentes de origen institucional (Derecho comunitario europeo) en la configuración del sistema español de Derecho internacional privado", Cursos de Derecho internacional de Vitoria-Gastéiz 1993, 1994, pp. 84-21

${ }^{67}$ Entre otros, pueden verse las consideraciones realizadas sobre Derecho uniforme y Derecho internacional privado, con especial incidencia en el régimen convencional: A. MALinTopPI, Diritto uniforme e diritto internazionale privato in tema di transporto, Milán, Guiffrè Editore, 1955, pp. 38-84.

${ }^{68}$ Respecto a la cuestión: U. BelintXon MARTín, "La confluencia de los distintos bloques normativos aplicables en materia de transporte internacional: divergencias y efecto distorsionador", en Petit Lavall, M.V., Martínez Sanz, F., y Recalde CasTELls, A. (Dirs.), La nueva ordenación del mercado de transporte, Madrid, Marcial Pons, 2013, pp. 15-20.

${ }^{69}$ Gaceta, 31 de julio de 1930.

${ }^{70}$ BOE, 11 de febrero de 1984.
} 
vas del Convenio UNCITRAL de 2008 (Reglas de Rotterdam) ${ }^{71}$ y por último el conjunto normativo de fuente institucional derivado de los Reglamentos de la UE.

51. Cabe subrayar que la LNM española supone, pese a ciertas soluciones legislativas criticables desde nuestra disciplina análisis internacional-privatista, un avance jurídico importante dentro de nuestro sistema autónomo al dotar al ordenamiento jurídico interno español de un marco legal moderno y sistematizado y que pretende fomentar además una mayor seguridad jurídica y previsibilidad ${ }^{72}$.

52. La Audiencia de Barcelona en esta resolución, concreta y delimita acertadamente el margen de maniobra contractual conflictual y material ${ }^{73}$ que cabe conferir a las partes ${ }^{74}$ en una relación de transporte marítimo internacional $7^{75}$ a la hora de determinar el tribunal estatal competente ${ }^{76}$. Además, es respetuosa con la tendencia ${ }^{77}$ del Derecho marítimo ${ }^{78}$ hacia su uniformidad normativa internacional ${ }^{79} \mathrm{y}$ el reconocimiento pleno de la autonomía de la voluntad de las partes ${ }^{80}$, la autorregulación ${ }^{81}$ y la nuclear importancia de los usos y prácticas mercantiles elaboradas por las empresas operadoras del sector ${ }^{82}$ que conocen bien las complejas realidades negociales y contractuales ${ }^{83}$. Y todo ello sin obviar el papel nuclear del objetivo de seguridad jurídica y previsibilidad a consolidar ${ }^{84}$ y conscientes de la citada complejidad y

\footnotetext{
${ }^{71}$ Sobre los Convenios Internacionales aplicables en el Derecho marítimo español puede verse: I. Arroyo MartínEz, "Derecho marítimo español y convenios internacionales. Luces y sombras", $A D M$, vol.16, 1999, pp. 21-79; J.J. Alvarez RuBIO, "Sector de la responsabilidad por contaminación del medio marino", Los foros de competencia judicial internacional en materia maritima, Vitoria-Gasteiz, Servicio central de publicaciones del Gobierno Vasco, 1993, pp. 89 y ss.

${ }^{72}$ Entre otros sobre los objetivos de la Ley de Navegación Marítima española puede verse: J.C. FuEnTE Gómez, "Principios y fines generales...", op. cit., pp. 361-366; J.L. GoÑ Etchevers, Temas de Derecho Marítimo, Madrid, Thomson Reuters Aranzadi, 2016, p. 383 y ss.

${ }^{73}$ Sobre el particular, G. Kaufmann-KoHLER, La clause d'élection de for dans les contrats internationaux, Frankfurt, 1980, p. 1 .

${ }^{74}$ Puede verse entre otros: J. CARrascosa GonzÁlez, "La autonomía de la voluntad conflictual y la mano invisible en la contratación internacional”, La Ley, $\mathrm{n}^{\circ}$ 7847, de 27 de abril de 2012.

${ }^{75}$ En relación a la evolución de la disciplina del Derecho marítimo, entre otros: J. Lopuski, "Les principales lignes d'évolution du Droit maritime privé:l'influence exercée par la pression des pays en développement”, D.M.F., 1987, pp. 217 y ss.

${ }^{76}$ En relación al carácter predominantemente dispositivo de algunos preceptos referentes a la LNM, ver la regulación del contrato de fletamento, en este sentido es muy clarificador el trabajo realizado sobre el Anteproyecto de Ley General de la Navegación Marítima del año 2006 por A. Emparanza Sobejano, "El contenido del contrato de fletamento", en EmparanzA Sobejano, A., (Dir.): Estudio sistemático de la Propuesta de Anteproyecto de Ley General de la Navegación Maritima, VitoriaGasteiz, Servicio Central de Publicaciones del Gobierno Vasco, 2006, pp. 327 y ss.

${ }^{77}$ Tal y como destaca A. Briggs, "The validity of floating choice of law and jurisdiction clauses", Lloyd's mar. and Com. Law Quart., 1986, pp. 508 y ss. En la misma orientación, J. RAMBERG, "Freedom of contract in maritime law", Lloyd's mar. and Com. law quart., 1993, pp. 178 y ss.

${ }^{78}$ En cuanto a la internacionalidad objetiva o intrínseca del Derecho del transporte marítimo puede verse entre otros: S.M. CARBone, Contratto di trasporto marittimo di cose, Milán, Tela Editoriale, 1988, pp. 55 y ss.

${ }^{79}$ Sobres el análisis particular de las concretas necesidades de armonización de un especifico sector de actuación normativa: R. Luzzatto, "Metodi di Unificazione del Diritto Marittimo e interpretazione Uniforme”, Dir Mar, 1999-I, pp.148-151.

${ }^{80}$ Sobre el particular, G. KaUfman-Kohler, La clause d'élection..., op. cit., p. 1.

${ }^{81}$ Respecto a la regulación y la autorregulación, entre otros: U. BeLINTXON MARTin, "El dilema en el conflicto del Taxi y el VTC: ¿La desregulación?”, Bitácora Millennium DIPr: Derecho internacional privado, núm. 9, 2019, pp. 1-13.

82 En relación a las insuficiencias de los Tratados multilaterales como cauce idóneo para la codificación internacional, la evolución europea del DIPr y otras alternativas, véase: J.C. FERNÁNDEZ RozAS, "La ordenación de las relaciones privadas internacionales a través de tratados en las postrimerías de su ciclo histórico", El Derecho internacional en el mundo multipolar del siglo XXI, Madrid, Iprolex, 2013, pp. 54-62.

${ }^{83}$ Entre otro sobre esta cuestión: U. BeLintXon MARTín, "Derecho Internacional Privado y transporte de viajeros por carretera: algunas cuestiones sobre jurisdicción y ley aplicable", $C D T$, vol. 8, nº 1, Marzo 2016, pp. 17-35.

${ }^{84}$ Pueden verse el Considerando 15 del RBI bis (Reglamento (UE) $\mathrm{n}^{\circ} 1215 / 2012$ del Parlamento europeo y del Consejo de 12 de diciembre de 2012 relativo a la competencia judicial, el reconocimiento y la ejecución de resoluciones judiciales en materia civil y mercantil), conforme a cuyo tenor, "Las normas de competencia judicial deben presentar un alto grado de previsibilidad y deben fundamentarse en el principio de que la competencia judicial se basa generalmente en el domicilio del demandado. La competencia judicial debe regirse siempre por este principio, excepto en algunos casos muy concretos en los que el objeto del litigio o la autonomía de las partes justifique otro criterio de conexión. Respecto de las personas jurídicas, debe definirse el domicilio de manera autónoma para incrementar la transparencia de las normas comunes y evitar los conflictos de jurisdicción"; e igualmente el Considerando 16 del R. Roma I (Reglamento (CE) n593/2008, de 17 de junio, sobre ley aplica-
} 
la diferente tipología de las relaciones contractuales dimanantes en este sector comercial (fletamento por tiempo, el fletamento por viaje, contratos de transporte de mercancías en buques de línea etc. ${ }^{85}$.

53. También acierta la Audiencia Provincial de Barcelona en su Auto de 18 de marzo de $2019^{86}$ al indicar expresamente en su Fundamento Jurídico Quinto sobre la aplicación de la doctrina del TJUE y el TS al supuesto enjuiciado que [...] Aplicado cuanto antecede al presente caso el artículo 25 del Reglamento CE 1215/2012 no queda relegado por la Ley española. Tampoco lo complementa o introduce requisitos de forma adicionales. Dicho precepto establece cómo debe celebrarse el acuerdo atributivo de competencia y fija la Ley conforme a la cuál debe examinarse la validez del acuerdo (la del Estado Miembro a cuyos tribunales se hayan sometido a las partes). Sólo si la cláusula de sumisión lo es en favor de los tribunales españoles puede enjuiciarse su validez con arreglo 1 artículo 468 de la LNM. Por todo ello, dado que el contrato de transporte se suscribió entre las partes litigantes, única a las que se refieren los conocimientos de embarque, la aplicación del mencionado art.25 Reglamento CE (RCL 1978, 2836) 1215 resulta procedente y ajustado a derecho la resolución recurrida [...].

54. La Audiencia Provincial de Madrid en su Auto de 5 de julio de $2019^{87}$ expone su interpretación en similares términos a las anteriores resoluciones y acierta de plano en la argumentación jurídica esgrimida en la presente resolución al establecer como criterio hermenéutico la aplicación prioritaria y prevalente de las normas procesales internacionales y europeas en materia de acuerdos atributivos de jurisdicción (artículo $25 \mathrm{RBI}$ bis), sobre las normas de origen interno (artículo $468 \mathrm{LNM})^{88}$.

55. En el supuesto concreto, que se activa en reclamación de los daños padecidos en la carga transportada, la demandada dedicada a la actividad de transporte marítimo planteó declinatoria por falta de competencia judicial internacional con base en una cláusula de sumisión a la High Court of Justice de Londres contenida en el conocimiento de embarque.

56. En este caso, la Audiencia en su razonamiento jurídico segundo, y en referencia a su jurisprudencia anterior, en concreto su Auto de 21 de julio de 2009 en relación al artículo 23 del antiguo RBI, hoy artículo 25 del RBI bis, viene a indicarnos que el citado precepto [...] convierte a los tribunales designados en el pacto de prorrogación de la competencia jurisdiccional, cumpliéndose determinados requisitos, en exclusivamente competentes, quedando obligados los tribunales de los restantes Estados a abstenerse de conocer. En su virtud, la existencia de un pacto de sumisión jurisdiccional expresa a favor de los tribunales de otro Estado comunitario obligará al tribunal españoles ante el que se hubiera presentado la demanda a aplicar las disposiciones contenidas en dicho precepto, art.23, que resultará por consiguiente aplicable, cuando no se infringen con su aplicación al caso ninguna de las competencias inderogables exclusivas previstas en el art. 22 ni se contravienen las reglas especiales previstas en materia de seguros, consumidores o contratos de trabajo [...].

57. Y además de ello añade que el artículo 23 del Reglamento 44/2001 prevé [...] que el acuerdo atributivo de competencia deberá celebrarse [...]; b) en una forma que se ajustare a los hábitos que las partes tuvieren establecido entre ellas; o c) en el comercio internacional, en una forma conforme a los

\footnotetext{
ble a las obligaciones contractuales), conforme al cual, y "Con el fin de contribuir al objetivo general del presente Reglamento que es la seguridad jurídica en el espacio judicial europeo, las normas de conflicto de leyes deben presentar un alto grado de previsibilidad. No obstante, el juez debe disponer de un margen de apreciación con el fin de determinar la ley que presenta los vínculos más estrechos con la situación".

${ }^{85}$ J.J. Álvarez Rubio, "Derecho privado y la UE: ¿armonización material o conflictual?”, en Goizueta Vértiz, J., y Cinfuegos Mateo, M., La eficacia de los derechos fundamentales de la UE: cuestiones avanzadas, Cizur Menor, Thomson Reuters Aranzadi, 2014, pp. 291-310.

${ }^{86}$ AAP de Barcelona (Sección 15ª), de 18 de marzo de 2019. Aranzadi. JUR/2019/97146.

${ }^{87}$ AAP de Madrid (Sección 28 ${ }^{\mathrm{a}}$ ), de 5 de julio de 2019. Aranzadi. AC 2019/1354.

${ }^{88}$ Respecto a la cascada de la especificidad, entre otros: entre otros: U. BELINTXON MARTín, Derecho europeo y transporte internacional por carretera, Cizur Menor, Thomson Reuters Aranzadi, 2015, pp. 41-49.
} 
usos que las partes conocieren o debieren conocer y que, en dicho comercio, fueren ampliamente conocidos y regularmente observados por las partes en los contratos del mismo tipo en el sector comercial considerado.

58. Dice además el tribunal que [...] En el presente caso estamos ante una atribución competencial a favor de los tribunales ingleses (en concreto, de la High Court of Justice de London) realizada por escrito en una cláusula contenida en un conocimiento de embarque. Esto satisface las aludidas exigencias de la normativa internacional.

59. Una desestimación de la pretensión recurrida que termina por justificar la Audiencia en su resolución al indicar en su razonamiento jurídico tercero que [...] no se ve el menor atisbo de fraude de ley o mala fe en el establecimiento de una cláusula de sumisión, siendo razonable el interés que en el comercio internacional puede existir por residenciar los litigios en tribunales que históricamente se encuentran más vinculados que otros en relación a las cuestiones concernientes al comercio marítimo ${ }^{89}$.

\section{Modificación del acuerdo atributivo de jurisdicción del artículo 25 RBI bis por sumisión tácita del artículo 26 del RBI bis. Primacía del Derecho europeo sobre el artículo 468 LNM}

60. En su Auto de 23 de mayo de 2017 la Audiencia Provincial de Castellón ${ }^{90}$ muy acertadamente en su fundamento de derecho tercero esgrime una muy correcta explicación de la modificación que recibe el actual artículo 25 del RBI bis respecto al antiguo artículo 23 del RBI y que pivota, en primer lugar sobre la supresión de la exigencia de que al menos uno de los contratantes esté domiciliado en un Estado miembro de la UE, siendo suficiente para la activación de la norma que las partes hayan acordado someter sus controversias a los tribunales de un Estado miembro de la UE. Y por otro, sobre la desvinculación total o completa del acuerdo atributivo de jurisdicción del resto del contrato no pudiendo ser impugnada la competencia del órgano jurisdiccional acordado por la sola razón de la invalidez del contrato (artículo 25.5).

61. Tras ello, el tribunal hace alusión de forma meridiana al principio de jerarquía normativa no dejando lugar a dudas respecto a la primacía jerárquica del Derecho de la Unión Europea, y por lo tanto lo dispuesto por el RBI bis (artículo 25), sobre las normas de origen interno o nacional, y en particular sobre lo transcrito en el artículo 468 de la LNM. De esta forma, y según acuerdo atributivo de jurisdicción que consta en anverso de conocimiento de embarque los tribunales de Rotterdam han sido designados como competentes para conocer.

62. No obstante dicho esto, no es menos cierto que en aplicación de lo dispuesto por el artículo 26 del propio RBI bis sobre la sumisión táctica en el asunto de autos el demandado al no impugnar la competencia mediante declinatoria con carácter previo a la contestación de la demanda, queda sometido a los juzgados y tribunales ante los que se interpuso la demanda reconvirtiendo o modificando la sumisión expresa a los tribunales de Rotterdam contenida en el anverso al conocimiento de embarque en una nueva sumisión a los juzgados y tribunales españoles que asumirán la competencia para el conocimiento del asunto.

\footnotetext{
${ }^{89}$ Sobre la acertada orientación de la presente resolución puede verse el excelente análisis de la amiga y profesora N. Magallón Elosegui, "Los acuerdos atributivos de jurisdicción a favor de un tribunal extranjero incluidos en un conocimiento de embarque: los usos y la libertad contractual en el sector marítimo. comentario al auto de 5 de julio de 2019 de la AAP de Madrid (Sección 28)", CDT, vol. 12, nº1, 2020, pp. 619-626.

${ }^{90}$ AAP de Castellón (Sección 3a , Civil), de 23 de mayo de 2017, Aranzadi. JUR /2018/26095.
} 


\section{Acuerdo atributivo de jurisdicción inserto en conocimiento de embarque. No apreciación de prevalencia del artículo 25 RBI bis sobre el artículo 468 LNM y la eficacia traslativa del conoci- miento de embarque del artículo 251 LNM}

63. Entre otras, la Audiencia Provincial de Barcelona en su auto/resolución emitida el 21 de diciembre de $2016^{91}$ desacierta completamente ante un supuesto litigioso que deviene de un contrato de transporte marítimo internacional con conocimiento de embarque, pues no acierta a la hora de valorar la transmisión y los efectos de la transmisión de un conocimiento de embarque y la calificación que merece la ausencia de consentimiento a la cláusula de sumisión expresa en favor del tribunal de comercio de Marsella en relación al artículo 251 de la LNM.

64. La resolución de instancia, muy acertadamente, estima la declinatoria de jurisdicción planteada por la demandada y declara la falta de jurisdicción del Juzgado para conocer de la demanda por considerar que la controversia tiene que someterse a tribunal extranjero (en este caso el tribunal de comercio de Marsella) y que es de aplicación la ley francesa según acuerdo de elección de ley recogido en el anverso del conocimiento de embarque. La acción se articula en petición y reclamación de los daños y perjuicios ocasionados por la naviera francesa con ocasión del transporte marítimo de una partida de langostinos desde el puerto de Cortés, en Honduras, con destino al puerto de Algeciras. Un transporte realizado en régimen de conocimiento de embarque y cuyo conocimiento de embarque no fue firmado ni por cargador ni por destinatario.

65. Ante esta tesitura por la demandada se presenta declinatoria de jurisdicción en aplicación del artículo 25 del RBI bis argumentando que esta norma de Derecho procesal civil internacional y europeo prevalece sobre los artículos 468 y 251 de la LNM por lo que la competencia exclusiva para conocer del litigio corresponde al tribunal de Marsella, y que el acuerdo es válido y oponible a terceros de acuerdo con la legislación aplicable, el derecho francés.

66. A partir de aquí la resolución de la citada Audiencia se torna en el encadenamiento de una cadena de errores y apreciaciones que contradicen no solo los usos y costumbres sectoriales, sino que además pretende reinterpretar por completo el artículo 25 del RBI bis y en especial la designación por tal precepto como ley rectora para verificar la validez material de los acuerdos de prórroga de la competencia de la ley del Estado miembro designado como competente para conocer de la controversia (en este caso concreto la ley francesa).

67. Este pronunciamiento y su línea argumental, que huelga decir ha sido revertida en ocasiones muy acertadamente por la propia Audiencia Provincial de Barcelona, como por ejemplo en su Auto de 13 de febrero de 2019 ya comentado en este trabajo, desnortó al operador jurídico ya que tras revisar muy detalladamente la jurisprudencia de nuestro máximo órgano jurisdiccional, el Tribunal de Justicia de la Unión Europea (en relación a la modificación operada por el antiguo artículo 17 del Convenio de Bruselas de 1968 sobre los acuerdos atributivos de jurisdicción que permitió presumir la existencia de consentimiento para la sumisión cuando existen al respecto, en el sector del comercio internacional considerado, usos comerciales que las partes conocen o debieran conocer), concreta que el marco legal aplicable tras la entrada en vigor de la LNM tiene una incidencia directa sobre las cláusulas de sumisión insertas en conocimientos de embarque, o en otros contratos de utilización de buque, sin distinguir aquellos acuerdos de sumisión que atribuyen competencia judicial internacional a los tribunales de un Estado miembro de la UE, de aquellos que atribuyen competencia jurisdiccional a juzgados y tribunales de terceros Estados y que no encuentran acomodo o respaldo en un Convenio internacional.

68. Una resolución ciertamente muy criticable que incluso se permite el lujo de indicar expresamente que la LNM [...] introduce modificaciones que afectan de manera expresa a las cláusulas de

${ }^{91}$ AAP de Barcelona (Sección 15ª Civil), de 21 de diciembre de 2016, Aranzadi. AC /2017/1872. 
sumisión insertas en conocimientos de embarque o en otros contratos de utilización del buque, modificaciones que obligan a revisar también la doctrina jurisprudencial $[\ldots]$

69. Volvemos a reiterar, el TJUE, ha sido clarificador mediante su jurisprudencia al respecto, entre otras en sus resoluciones de 19 de junio de 1984, asunto Tilly Russ (C-71/83) ${ }^{92}$; de 16 de marzo de 1999, asunto Castelleti (C-159/97) $)^{93}$; y de 9 de noviembre de 2000, asunto Coreck Maritime GmbH y Handelsveen BV y otros $(\mathrm{C}-87 / 98)^{94}$, en las que concluye que [...] se presume que las partes contratantes han dado su consentimiento a las cláusulas atributivas de competencia cuando el comportamiento de las mismas corresponda a un uso que rige en el ámbito del comercio internacional en el que operan y que conocen o debieran conocer, y que las exigencias concretas que engloban el concepto de forma conforme a los usos deben valorarse exclusivamente a la luz de los usos comerciales del sector del comercio internacional de que se trate, sin tener en cuenta las exigencias particulares que pudieran establecer las disposiciones nacionales.

70. En efecto, la jurisprudencia del TJUE ha considerado que existe un uso en el sector comercial concreto cuando, en particular, los operadores de dicho sector siguen un comportamiento determinado de modo general y regular al celebrar cierta clase de contratos. Y además de ello entiende que la cláusula atributiva de jurisdicción puede ser invocada frente al tercero tenedor del conocimiento, desde el momento en que, con arreglo al Derecho nacional aplicable, es decir la ley del Estado miembro designado como competente para conocer de la controversia según el artículo 25 RBI bis, el tenedor del conocimiento se subroga en los derechos y obligaciones del cargador.

71. De este modo, el tercero tenedor se convierte en [...] titular, a la vez, de todos los derechos y de todas las obligaciones que figuran en el conocimiento, incluidas las relativas a la prórroga de competencia. En definitiva, una cláusula atributiva de competencia acordada entre un porteador y un cargador e incluida en un conocimiento de embarque produce efectos frente al tercero tenedor del conocimiento de embarque siempre y cuando al adquirirlo, éste haya sucedido al cargador en sus derechos y obligaciones en virtud del Derecho aplicable. Por el contrario, si el tercero tenedor no ha sucedido al cargador, no podrá oponérsele la cláusula atributiva de competencia, a no ser que haya dado su consentimiento a ella. Y su oponibilidad al destinatario o a terceros adquirentes del conocimiento de embarque son ampliamente conocidos y regularmente observados por las partes en el sector de transporte marítimo, por ser una cláusula conforme a los usos del comercio internacional.

72. No se comprende pues que una vez hecha esta referencia a la jurisprudencia del TJUE, la Audiencia Provincial de Barcelona en la citada resolución y suplantando al legislador europeo y al TJUE venga a concluir en los párrafos 21,22 y 23 de su fundamento jurídico cuarto que la referencia del artículo 25 del RBI bis al "con arreglo al Derecho aplicable" [...] no es el del Estado miembro al que se hayan sometido las partes (en este caso, Francia), como dispone el artículo 25 del Reglamento, sino el que decida el Juez nacional. Lo cual es del todo lógico, pues si el Derecho aplicable es el del lugar al que se someten las partes, estaríamos anticipando los efectos de las cláusulas de jurisdicción [...].

[...] En definitiva, entendemos que la eficacia traslativa del conocimiento de embarque ha de analizarse con arreglo al Derecho español, y en concreto, conforme al artículo 251 de la LNM [...]. Esto es, el adquirente del conocimiento de embarque sólo quedará vinculado por la cláusula de sumisión si ha sido negociada individual y separadamente al adquirir el título [...].

[...] Por lo expuesto no es aplicable la Ley del lugar al que se someten las partes, ni la del lugar de emisión del conocimiento de embarque. Si así se entendiera, se estaría permitiendo que la cláusula adelantara sus efectos, imponiendo su contenido a las partes en el negocio de cesión (en este caso, dos empresas españolas) $[\ldots]$.

\footnotetext{
${ }^{92}$ Recuperado de: www.curia.europa.eu.

${ }^{93}$ Recuperado de: www.curia.europa.eu.

${ }^{94}$ Recuperado de: www.curia.europa.eu.
} 
73. Claro está que la interpretación de la Audiencia Provincial de Barcelona es contraria al Derecho europeo así como la estimación del recurso de apelación ${ }^{95}$. Una interpretación equivocada que proyecta de nuevo la propia Audiencia de Barcelona muy recientemente en su sentencia de 23 de julio de $2019^{96}$, apartado 24 de su Fundamento Jurídico Segundo al indicar como en anteriores pronunciamientos que [...] Además de la validez de la cláusula de sumisión, el TJUE exige que el tercero haya sucedido en los derechos y obligaciones del cargador "con arreglo al Derecho nacional aplicable". Y ese Derecho no es el del Estado Miembro al que se hayan sometido las partes (en este caso, Inglaterra), como dispone el artículo 25 del Reglamento, sino el que decida el Juez nacional. Lo cual es del todo lógico, pues si el Derecho aplicable es el del lugar al que se someten las partes, estaríamos anticipando los efectos de la cláusula de sumisión [...]. Téngase en cuenta que el TJUE precisamente determina en sus sentencias TNT vs AXA de 4 de mayo de 2010 (asunto C-533-08) ${ }^{97}$ y Nipponkoa Insurance de 13 de diciembre de 2013 (asunto C-452-12) ${ }^{98}$ que lo que se pretende o busca con tal concreción o determinación (la de la ley rectora para verificar la validez material de los acuerdos de prórroga o atributivos de jurisdicción) es garantizar la seguridad jurídica, la evitación de procedimientos paralelos en el seno de la Justicia en la UE, la libre circulación y el reconocimiento y ejecución de las resoluciones judiciales en el seno de la UE y la previsibilidad de resultado 99 .

\section{La inaplicación del acuerdo atributivo de jurisdicción inserto en carta de porte marítima suscri- ta entre transportista contractual y transportista efectivo al cargador que suscribió conocimiento de embarque sin incorporación de sumisión expresa con el porteador contractual}

74. La Audiencia Provincial de Barcelona en su auto/resolución emitida en fecha 7 de octubre de 2019 reflexiona sobre ciertas cuestiones de transcendental importancia en relación a los acuerdos atributivos de jurisdicción, los artículos 25 RBI bis y 468 LNM, y la vinculación del cargador mediante un acuerdo atributivo de jurisdicción a los tribunales de Londres inserto en la carta de porte marítima (Sea Waybill) firmada por porteador contractual y porteador efectivo, ante la inexistencia de pacto de sumisión expresa contenido en el conocimiento de embarque (Bill of Lading) concretado entre el propio cargador y el transportista contractual.

75. El supuesto litigioso que enfrenta a la aseguradora de la cargadora, Catalana Occidente SA con domicilio en Barcelona, con los codemandados Rhenus Logistics SAU -transportista contractual con domicilio en Barcelona-, y Maersk Spain SLU -transportista efectivo-, tiene por objeto una demanda de indemnización por los daños y perjuicios ocasionados tras la pérdida total de la mercancía transportada ante el incendio del buque, su abandono y la declaración de avería gruesa cerca de Omán.

76. Como indicamos el conocimiento de embarque firmado entre empresa cargadora y empresa transportista contractual no incorpora cláusula de sumisión jurisdiccional, en cambio en la carta de porte marítima suscrita entre Rhenus y Maersk si se incorpora una cláusula de sumisión expresa a la High Court of Justice de Londres.

\footnotetext{
${ }^{95}$ Un Derecho europeo que aporta frente a la diversidad de fuentes una tendencia armonizadora en materia de Derecho del transporte, en este sentido puede verse entre otros: I. Bon Garcín, M. Bernadet e Y. Reinhard, Droit des transports, Paris, Dalloz, 2010, pp. 2 y ss.

${ }^{96}$ SAP Barcelona (Sección 15ª de 23 de julio de 2019. AC/2019/1270. Recuperado de Westlaw Aranzadi.

97 www.curia.europa.eu.

98 www.curia.europa.eu.

99 Entre otros sobre los objetivos de la Ley de Navegación Marítima española puede verse: J.C. FuENTE GómEz, "Principios y fines generales de la Ley de Navegación Marítima", en Petit Lavall, M.V., y Puetz, A. (Dirs), La eficiencia del transporte como objetivo de la actuación de los poderes públicos: liberalización y responsabilidad, Madrid, Marcial Pons, 2015, pp. 361366. Sobre los diversos anteproyectos y trabajos preparatorios vid. J.L. GoÑ ETcheVERs, Temas de Derecho..., op. cit., p. 383 y ss.
} 
77. De esta manera la sala, muy acertadamente, interpreta que la cláusula de jurisdicción a los tribunales de Londres inserta en la carta de porte marítima no vincula a la empresa cargadora (demandante en este procedimiento), y ante la ausencia de un acuerdo de sumisión de estas características en el conocimiento de embarque original los tribunales españoles tienen competencia para conocer del trayecto marítimo ejecutado desde el puerto de Hong Kong hasta el puerto de Barcelona.

78. En efecto, la carta de porte marítima firmada por transportista contractual y transportista efectivo, además de no ser un título valor representativo de las mercancías, como sí lo es el conocimiento de embarque, no vincula a la remitente o cargadora de la mercancía que contrató con Rhenus (transportista contractual) la materialización del transporte. Recuérdese, además, que la carta de porte ostenta única y exclusivamente un valor probatorio en el sentido de que da fe, salvo prueba en contrario, de las condiciones del contrato y de la recepción de la mercancía por el transportista. Es decir, en este caso la recepción de las mercancías a transportar por parte del porteador efectivo viene de manos del transportista contractual y no del remitente o cargador original con el que suscribió el transportista contractual un conocimiento de embarque sin inserción o previsión de cláusula de jurisdicción. Por lo tanto, el cargador es totalmente ajeno a la relación contractual de transportar entre transportista contractual y transportista efectivo por lo que ninguna proyección, ni validez, puede tener sobre dicho cargador la cláusula de sumisión expresa a los tribunales de Londres inserta en la citada carta de porte marítima ${ }^{100}$. Cabría únicamente plantearse, aunque no es el supuesto de Autos y tampoco es objeto de las presentes consideraciones, si el tercero destinatario, ajeno a la controversia suscitada en este caso, pudiera verse sometido o vinculado por tal cláusula atributiva de jurisdicción inserta en la carta de porte.

79. En este mismo sentido se pronunció también la Audiencia de Barcelona en su sentencia de 23 de julio de 2019 en la que entendió que la cláusula de jurisdicción incorporada en la carta de porte marítima vinculaba única y exclusivamente a las porteadoras contractuales y al porteador efectivo, y no al cargador, Nestlé S.A, quien había contratado con la empresa de logística e intermediaria JSV Logístic la gestión del envío y su ejecución, quien contrató a Atlas Forwarding que a su vez contrató a la porteadora efectiva WEC.

80. Recuérdese además que según lo dispuesto por el TJUE, Sala Tercera, en su sentencia de 23 de octubre de 2014, Asunto C-305/13 ${ }^{101}$, el contrato de comisión de transporte puede ser considerado un contrato de transporte siempre y cuando el contrato tenga como objeto principal de comisión el transporte de mercancías. Es decir, que la ejecución del transporte sea considerada la actividad principal, y no meramente accesoria, de la relación contractual viéndose el comisionista obligado a garantizar la propia ejecución del transporte de mercancías y a asumir mediante la subrogación la posición del transportista, sus derechos y obligaciones. Cuestión que le corresponderá verificar al órgano jurisdiccional que conozca de la causa según criterios tales como la prestación real realizada, la finalidad de la relación contractual y el conjunto de obligaciones de la parte que deba realizar la prestación característica del contrato. El Tribunal de Justicia ya se había manifestado sobre esta cuestión al interpretar el Convenio de Roma de 1980, en el asunto Intercontainer Interfrigo (STJUE, de 6 de octubre de 2009, Asunto C$133 / 08)^{102}$, respecto a una cuestión similar en relación al artículo 4.4 del citado Convenio. En dicha ocasión el Tribunal dictaminó que una de las finalidades del citado precepto era precisamente incrementar el ámbito de aplicación de la norma de Derecho internacional privado regulada en el último inciso del artículo 4.4 del Convenio y así permitir considerar como contratos de transporte, además de los contratos de fletamento para un solo viaje, otros contratos que tuviesen como objeto principal la realización del transporte de mercancías ${ }^{103}$. De esta forma se dispuso, al igual que en esta ocasión, y en relación a

\footnotetext{
${ }^{100}$ Sobre esta cuestión entre otras: J.J. Álvarez RuBIO, "Contracts for the international carriage of goods: jurisdiction and arbitration under the new UNCITRAL Convention 2008", Yearbook Private International Law, vol.11, 2009, pp. 171-191.

${ }^{101}$ www.curia.europa.eu

102 www.curia.europa.eu

${ }^{103}$ Sobre esta cuestión entre otros: U. BelintXon MarTín, "Ley aplicable a los contratos internacionales en defecto de
} 
la determinación del objeto principal del contrato, que procedía tomar en consideración la finalidad de la relación contractual y el conjunto de las obligaciones asumidas por la parte que realiza la prestación característica del contrato ${ }^{104}$.

81. Expuesto lo anterior, si cabría resaltar que la Audiencia Provincial de Barcelona en el referido Auto de fecha 7 de octubre de 2019 no se detiene a valorar los foros de competencia objetivos del RBI bis que se abren a elección de la parte demandante para la interposición de la correspondiente acción tanto frente al transportista contractual como frente al transportista efectivo (activando frente a este último la denominada acción directa). Es decir, que la Audiencia estima la competencia judicial internacional de los juzgados y tribunales de Barcelona sin concretar en base a qué norma y/o a qué foros se le atribuye ésta. Un ejercicio que hubiese permitido vislumbrar de forma meridianamente clara y a la luz de la jurisprudencia del TJUE las opciones procesales abiertas para la parte actora. Como bien es sabido, y los hemos reiterado de una u otra forma en el presente trabajo, en ausencia de Convenio internacional multilateral especial que regule la competencia judicial internacional, el RBI bis contiene entre sus previsiones preceptos dedicados expresamente a ello en la sección 2 sobre competencias especiales. En particular, el artículo 7.1 en materia contractual ${ }^{105}$ se divide en una norma general y dos vertientes contractuales concretas (compraventa de mercaderías -7. 1.a- y prestación de servicios ${ }^{106}$-7.1. b-).

82. En este caso al tratarse de una relación contractual de transportar será de aplicación la variante de prestación de servicios normativizada en el citado artículo 7.1.b RBI bis. Un concepto, el de prestación de servicios, que debe ser interpretado de manera autónoma y proyectándose sobre los contratos que generan para el transportista, o porteador, tanto una obligación de medios como una obligación de resultado ${ }^{107}$. Término en el que debe quedar incardinado el contrato de transporte marítimo internacional de mercancías.

83. El TJUE en diversas ocasiones ha precisado muy correctamente para una prestación de servicios cuáles deben identificarse como los lugares de un Estado miembro de la UE en el que hayan sido o deban ser prestados los servicios. Así lo ha hecho perfectamente en sus sentencias de 9 de julio de $2009^{108}, 11$ de julio de $2018^{109}$ y 7 de noviembre de $2019^{110}$.

84. El TJUE en su sentencia Peter Rehder vs. Air Baltic del año 2009 vino a establecer claramente que, ante una controversia en materia de transporte internacional de personas aéreo, siempre y cuando se cumplan los requisitos de aplicación del RBI bis, la parte demandante podrá interponer acción ante el tribunal del lugar del Estado miembro en el que, según el contrato, hayan o deban ser prestados

elección: la interpretación del artículo 4 del Convenio de Roma y su proyección sobre el Reglamento Roma I", La Ley Unión Europea, $\mathrm{n}^{\mathrm{o}} 22$, enero de 2015, pp. 55-60.

${ }^{104}$ Sobre las presunciones especiales del art. 4 del Convenio de Roma y la inaplicación del art. 4.2 a los contratos de transporte de mercancías: P.A. De Miguel Asensio, "La Ley aplicable en defecto de elección a los contratos internacionales: El artículo 4 del Convenio de Roma de 1980”, La Ley, XVI, 4 de abril de 1995, pp. 1-7.

${ }^{105}$ Respecto al artículo 5 del RBI (actual artículo 7 del RBI bis) puede verse entre otras las consideraciones expuestas por, M. Virgós Soriano y F.J. Garcimartín Alférez, Derecho procesal ..., op. cit., pp. 141-158.

${ }^{106}$ Sobre los contratos de prestación de servicios y su delimitación (artículo 7.1.b del RBI bis) pueden verse las reflexiones realizadas por el profesor P. A. De Miguel Asensio, "El lugar de ejecución de los contratos de prestación de servicios como criterio atributivo de competencia”, en J. Forner Delaygua, C. González Beilfuss, R. Viñas Farré (Coords.), Entre Bruselas y la Haya: Estudios sobre la unificación internacional y regional del Derecho internacional privado, Liber Amicorum Alegría Borrás, Madrid, Marcial Pons, 2013, pp. 291-307.

${ }^{107}$ En relación a la noción económica del contrato de prestación de servicios empleada por el artículo 5.1.b R.44/2001 (Hoy 7.1.b R.1215/2012) y el objeto principal de este tipo de contratos que comprenden y generan tanto una obligación de medios, como una obligación de resultado, pueden verse la consideraciones realizadas por los profesores A.L. CALvo CARAvaCA y J. Carrascosa GonzÁlez, "Contratos internacionales (I): Competencia judicial y Ley aplicable", Derecho del Comercio Internacional, Madrid, Colex, 2012, pp. 493-497.

${ }^{108}$ STJUE de 9 de julio de 2009. TJCE/2009/219. Recuperado de Westlaw Aranzadi.

109 STJUE de 11 de julio de 2018. TJCE/2018/185. Recuperado de Westlaw Aranzadi.

${ }^{110}$ STJUE de 7 de noviembre de 2019. TJCE/2019/243. Recuperado de Westlaw Aranzadi. 
los servicios de transporte. En efecto, la parte actora podrá interponer la demanda ante el lugar de origen o el lugar de destino del transporte internacional de personas aéreo, sin descuidar, la confluencia característica de esta clase de foros especiales por razón de la materia y el foro general del domicilio de la parte demandada que también podrá ser elegido por la actora ${ }^{111}$. Lo recoge así expresamente nuestro máximo órgano jurisdiccional en el apartado 43 de la resolución indicando [...] que tanto el lugar de salida como el lugar de llegada del avión son los lugares de prestación principal de los servicios que son objeto de un contrato de transporte aéreo [...]. Acierta el TJUE al advertir que tales lugares son los que presentan un vínculo directo con los referidos servicios y que además estos lugares son los que presentan un vínculo suficiente de proximidad con los elementos materiales del litigio.

85. El máximo órgano jurisdiccional de la UE vuelve a interpretar el referido artículo del RBI bis en su sentencia Zurich Insurance vs. Abnormal Load Services de 11 de julio de 2018, aunque en esta ocasión en relación a un contrato de transporte de mercancías. En su apartado 14 interpreta y concreta cuáles son los tribunales ante los que puede interponerse una acción derivada de un incumplimiento contractual en la materia al indicar que tanto el lugar de carga de la mercancía como el lugar de descarga o entrega de la mercancía son activables. Dicho apartado expresamente recoge que el artículo 7.1.b RBI bis (antiguo 5.1.b RBI) [...] debe interpretarse en el sentido de que, en el marco de un contrato de transporte de una mercancía entre Estados miembros en varias etapas y por medios de transporte diferentes, como sucede en el litigio principal, tanto el lugar de expedición como el lugar de entrega de la mercancía constituyen lugares de prestación del servicio de transporte en el sentido de dicha disposición [...]. Obviamente ambas opciones coexisten y concurren con el referido foro general del domicilio del demandado.

86. Finalmente, en su reciente sentencia EasyJetAirline de 7 de noviembre de 2019, el TJUE vuelve a reiterar el citado criterio hermenéutico para el ámbito de los transportes aéreos. Dispone el Tribunal en el apartado 42 de la citada resolución que [...] de la jurisprudencia del Tribunal de Justicia resulta que la norma de competencia especial en materia de prestación de servicios, prevista en el artículo 7, punto 1, letra b), segundo guion, del Reglamento $n^{\circ} 1215 / 2012$, designa como competente para conocer de una demanda de compensación basada en un contrato de transporte aéreo de personas, a elección del demandante, el tribunal en cuya demarcación se halle el lugar de salida o el lugar de llegada del avión, tal y como dichos lugares estén previstos en el contrato [...]. Nuevamente ambas opciones en concurrencia con lo dispuesto por el artículo 4 del RBI bis.

87. La justificación del foro general del artículo 4 del RBI bis citado radica en la garantía que ofrece para los derechos de defensa de la parte demandada y la efectividad de la futura resolución. Un foro general que junto a los referidos foros alternativos o de ataque, a elección de la parte actora, configura una suerte de posibilidades suplementarias por razón de una concreta materia y en atención a criterios intrínsecos a cada relación contractual controvertida y conforme a factores de proximidad del objeto litigioso (lugar de carga y lugar de destino o descarga de las mercancías) ${ }^{112}$. En esencia, una combinación de criterios de características personales y territoriales con criterios de atribución neutros y técnicas de protección de la parte más débil de la relación contractual ${ }^{113}$.

88. Queda así descartada la aplicación para este caso de los foros de competencia judicial internacional en materia de seguros de la sección 3, artículos 10 a 16 del RBI bis para aquellos supuestos en los que la aseguradora de la parte damnificada se posiciona en lugar de esta como parte actora frente a la parte incumplidora del contrato de transporte internacional de mercancías por mar.

111 J.L. Iriarte Ángel, El contrato de embarque ..., op. cit., pp. 100 y ss. Obsérvense los artículos 4.1 y 5.1 del RBI bis (artículos 2.1 y 3.1 del antiguo RBI).

112 J.J. Álvarez Rubio, Derecho Marítimo y Derecho Internacional Privado: algunos problemas básicos, Servicio de publicaciones del Gobierno Vasco, 2000, pp. 53-55.

${ }^{113}$ En este sentido entre otros puede verse las referencias a la competencia judicial internacional y ley aplicable realizadas sobre el contrato de transporte por A.L. Calvo Caravaca y J. Carrascosa González, "Contratos Internacionales II: Algunos contratos”, Derecho internacional privado, 15 a Edición, Granada, Editorial Comares, 2014, pp. 921-926. 
89. Por último, y a pesar de no ser necesaria tal referencia en el Auto, la Audiencia Provincial de Barcelona aprovecha el Fundamento de Derecho Tercero de la resolución para referirse una vez más de forma dubitativa, o cuanto menos poco esclarecedora, al trinomio compuesto por el artículo 25 del RBI bis y los artículos 468 y 251 LNM. Nuevamente, como ya lo hizo en resoluciones anteriores, realiza una interpretación oscura, o cuanto menos no contundente, sobre la validez material de la sumisión expresa al indicar en el párrafo cuarto del citado Fundamento de Derecho que [...] la cuestión con arreglo a qué Derecho nacional debe apreciarse si el tercero tenedor del conocimiento de embarque ha sucedido al cargador debe ser resuelta por el Juez nacional [...]. Es decir, esta interpretación o referencia realizada en la resolución no se concreta en los términos del artículo 25 del RBI bis que indica indubitadamente que la cuestión de la validez material del acuerdo atributivo de jurisdicción inserto en un conocimiento de embarque debe ser resuelta por el juzgado o tribunal designado como competente en la propia cláusula de sumisión expresa.

\section{Consideraciones Finales}

90. En definitiva, y en relación a la interpretación ofrecida por nuestros juzgados y tribunales sobre la determinación del régimen normativo aplicable a las cláusulas atributivas de jurisdicción contenidas en los conocimientos de embarque, cabe indicar que, pese a ciertas excepciones reseñables y el debate jurídico que suscitan, se están resolviendo mayormente de forma acertada al subrayar la primacía en la aplicación del artículo 25 del RBI bis sobre las previsiones contenidas en la LNM. La coexistencia de los diversos bloques normativos que confluyen en este especial sector del transporte marítimo internacional de mercancías requiere de un descenso particularizado en cada supuesto concreto para así poder seleccionar adecuadamente la norma concreta al amparo de la cual ha de ser analizada la cláusula atributiva de jurisdicción correspondiente.

91. El ordenamiento jurídico español evidencia una compleja maraña jurídico-normativa que distorsiona la interacción entre bloques normativos, y permite interpretaciones jurisprudenciales en materia de cláusulas de jurisdicción y arbitraje contrarias a los usos y costumbres del sector. Esto sin duda evidencia, en cierta medida, el fracaso de una norma que proyecta una clara declaración de intenciones en su preámbulo al indicar que el objeto final de la norma es armonizar el ordenamiento jurídico de aplicación al Derecho marítimo internacional y aportar una mayor dosis de seguridad jurídica y previsibilidad mediante el respeto a la regla de especialidad y la coordinación de los distintos bloques normativos en presencia, y que luego no respeta.

92. Por ello es necesario subrayar que en un sector tan complejo y singular como el del Derecho del transporte marítimo internacional es muy positivo, y acertado, sin perjuicio de las particularidades presentes en cada una de las modalidades de contratación, que un texto de estas características (LNM) sea respetuoso con la libertad contractual reconocida tradicionalmente a todas las partes interesadas en este ámbito. La internacionalización de las relaciones contractuales proyectada sobre el ámbito del comercio requiere favorecer un proceso de autorregulación que permita generar una desnacionalización o deslocalización del régimen normativo regulador del comercio internacional.

93. Y desde luego, ante la falta de coordinación de los distintos bloques normativos, es deseable desde nuestra perspectiva de estudio que las instituciones europeas e internacionales impulsen la creación de nuevas pautas de ordenación de normas como las contenidas en el Convenio de Viena sobre el Derecho de los Tratados de 23 de mayo de 1969 que reparen en los criterios establecidos por el TJUE sobre la regla de especialidad.

94. La inadecuada orientación legislativa del artículo 468 LNM no es una excepción en los últimos tiempos para la disciplina del Derecho del transporte internacional, pues se viene acrecentando 
de forma exponencial una derivada alarmante de nacionalismo jurídico, y de protectorados nacionales internos inaceptables, a golpe de legislar sin mesura bordeando, cuando no claramente contraviniendo, la legalidad o el Derecho europeo. Y esto tiene una incidencia significativa en el tráfico marítimo internacional pues no deja de plantear distorsiones en su aplicación práctica al contravenir los usos y costumbres inveterados y aceptados por las empresas operadoras en el sector.

95. No obstante, como decimos y como hemos podido analizar a lo largo del trabajo, mayoritariamente, aunque no unánimemente, nuestros juzgados y tribunales están aplicando correctamente la primacía del Derecho europeo y la regla de especialidad desplazando una corriente minoritaria que ha optado por aplicar un concepto de nacionalismo jurídico anquilosado en el tiempo que en nada beneficia al operador jurídico-empresarial, ni nada aporta al binomio seguridad jurídica y previsibilidad de resultado impuesto y exigido jurisprudencialmente por el TJUE.

96. Por último, simplemente volver a reseñar que la proyección normativa de la persona legisladora respecto a los condicionantes para la validez de las cláusulas atributivas de jurisdicción es un desacierto. Una redacción respetuosa con la realidad sectorial y con el Derecho europeo e internacional hubiera sido aquella que enfatizase en la dimensión procesal del reconocimiento de las mismas en el ordenamiento jurídico español. El citado posicionamiento legislativo a sensu contrario implica la escasa repercusión práctica de nuestra norma y la huida definitiva de las empresas operadoras hacia jurisdicciones o prácticas arbitrales más acordes con el estado actual de las cosas en este importante sector comercial. 